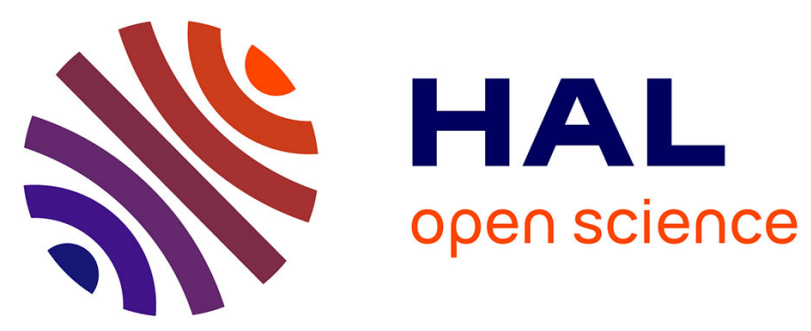

\title{
Synthesis of a magnetically separable LDH-based S-scheme nano-heterojunction for the activation of peroxymonosulfate towards the efficient visible-light photodegradation of diethyl phthalate
}

\author{
Arezou Fazli, Marcello Brigante, Alireza Khataee, Gilles Mailhot
}

\section{To cite this version:}

Arezou Fazli, Marcello Brigante, Alireza Khataee, Gilles Mailhot. Synthesis of a magnetically separable LDH-based S-scheme nano-heterojunction for the activation of peroxymonosulfate towards the efficient visible-light photodegradation of diethyl phthalate. Applied Surface Science, 2021, 559, pp.149906. 10.1016/j.apsusc.2021.149906 . hal-03350720

\author{
HAL Id: hal-03350720 \\ https://hal.science/hal-03350720
}

Submitted on 21 Sep 2021

HAL is a multi-disciplinary open access archive for the deposit and dissemination of scientific research documents, whether they are published or not. The documents may come from teaching and research institutions in France or abroad, or from public or private research centers.
L'archive ouverte pluridisciplinaire HAL, est destinée au dépôt et à la diffusion de documents scientifiques de niveau recherche, publiés ou non, émanant des établissements d'enseignement et de recherche français ou étrangers, des laboratoires publics ou privés. 
Synthesis of a magnetically separable LDH-based S-scheme nano-

heterojunction for the activation of peroxymonosulfate towards the efficient visible-light photodegradation of diethyl phthalate

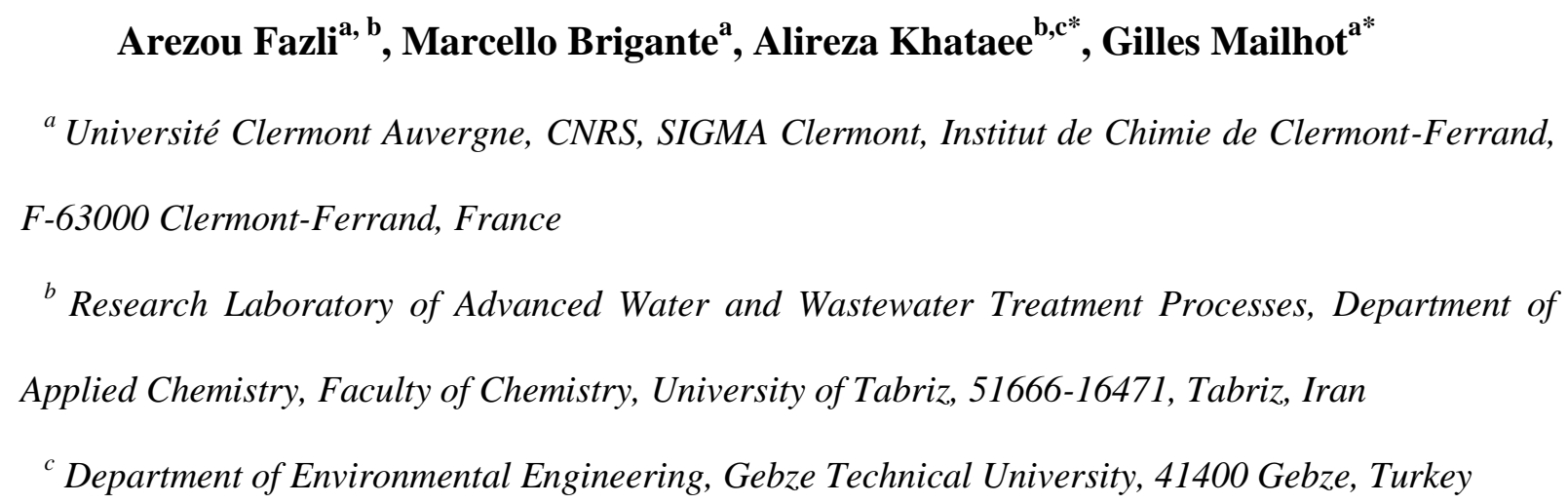




\section{Abstract}

Herein, a stable and S-scheme $\mathrm{Fe}_{3} \mathrm{O}_{4} @ \mathrm{CuCr}-\mathrm{LDH}$ nanocomposite was synthesized and used for the photocatalytic degradation of diethyl phthalate (DEP) through the activation of peroxymonosulfate (PMS). In comparison with pure $\mathrm{Fe}_{3} \mathrm{O}_{4}$, and $\mathrm{LDH}$, the $\mathrm{Fe}_{3} \mathrm{O}_{4} @ \mathrm{CuCr}-\mathrm{LDH}$ nanocomposite demonstrated significantly enhanced photocatalytic activity due to its Sscheme charge-carrier migration mechanism. The prepared composite was also magnetically recoverable from the treated water which is favorable to avoid the production of secondary pollution. The integration of the composite and visible light showed the presence of a synergy factor of 14 for the degradation of diethyl phthalate. However, the photocatalytic performance of $\mathrm{Fe}_{3} \mathrm{O}_{4} @ \mathrm{CuCr}-\mathrm{LDH}$ was dependent on the different physicochemical parameters; wherein, the higher degradation efficiency was achieved using the solution $\mathrm{pH}$ of 8, the catalyst, DEP, and PMS concentrations of $1 \mathrm{~g} \mathrm{~L}^{-1}, 20 \mathrm{mg} \mathrm{L}^{-1}$, and $8 \mathrm{mM}$, respectively. The high photocatalytic activity of the catalyst was maintained after 5 consecutive reaction runs and the stability of the material was proved by the XPS. Moreover, the ICP-AES analysis proved that the leaching of $\mathrm{Fe}, \mathrm{Cr}$, and $\mathrm{Cu}$ is lower than the standard concentration in the drinking water. Finally, the mineralization ability and the decreased toxicity of the treated solution of DEP were assessed.

Keywords: Visible light photocatalysis; Peroxymonosulfate; S-scheme; Layered double hydroxide; Diethyl phthalate. 


\section{Introduction}

The wide-ranging usage of phthalates in the different industrial products such as paints, medical devices, lubricants, adhesives, and packing products resulted in the occurrence of these compounds in the wastewater [1]. According to the literature review [2], the United States Environmental Agency, as well as, the European Union, have classified the phthalates as the main pollutants which have arisen the great concern. As the phthalates are ubiquitous in the environment, the human being has been environmentally exposed to the various kinds of them. However, these toxic and carcinogenic compounds have been widely declared to be the disrupting agents for the normal endocrine system which can subsequently damage the body organs and influence the metabolic, cardiovascular, and immune systems in people [1]. Hence, various potential adverse health risks of phthalate wastewater have garnered the attention of different researchers from all over the world [3]. It has been acknowledged that the traditional wastewater treatment methods are insufficient for the thorough removal of these compounds from the water bodies [4]. The presently available sulfate radical-based advanced oxidation processes (SR-AOPs) relying on the generation of the reactive sulfate radicals $\left(\mathrm{SO}_{4}{ }^{--}\right)$with the high oxidation potential and a half-life time $\left(\mathrm{E}_{0}=2.5-3.1 \mathrm{~V}\right.$ and $\mathrm{t}_{1 / 2}=30-40 \mu \mathrm{s}$, respectively) have been considered for the degradation of a wide range of phthalates [5]. Persulfate (PS) and peroxymonosulfate (PMS) have been applied as the main sources for the generation of sulfate radicals. PMS has a higher reactivity due to its asymmetric structure; in consequence, it has been widely used as the oxidant for the degradation of diverse kinds of water pollutants through the AOPs [6]. Furthermore, it has been already affirmed that PMS can be activated by heat, UV light, and transition metals [7]. Nonetheless, Ruobai and et al. [8] have previously reported that the integration of light and metal ions can be an accelerated activating approach for the decomposition of PMS by the occurrence of redox cycling of metal ions during the irradiation [8]. To date, different metal 
ions such as $\mathrm{Co}, \mathrm{Fe}$, and Mn have been used to efficiently activate PMS [9]. To avoid the metal ion-leaching to the water, the researchers have worked on the numerous heterogeneous photocatalysts comprising the transition metals to activate the PS and PMS. To this end, metal oxides such as $\mathrm{Fe}_{3} \mathrm{O}_{4}[10]$ and $\mathrm{CuO}$ [11] were ascertained to possess high activity for PMS activation. Among different metal oxides, $\mathrm{Fe}_{3} \mathrm{O}_{4}$ is of great importance due to its magnetic property. Accordingly, $\mathrm{Fe}_{3} \mathrm{O}_{4}$ and its incorporated form with another nanomaterial could be recycled from the reactor by applying an external magnetic field [12]. On the other hand, by possessing a special structure, extensive surface area, low cost, and narrow bandgap semiconductor properties, 2D structured layered double hydroxides (LDHs) have been categorized as promising photocatalysts in water treatment applications [13]. LDHs have the specific formula of $\left[\mathrm{M}_{1-\mathrm{x}}{ }^{2+} \mathrm{M}_{\times}{ }^{3+}(\mathrm{OH})_{2}\right]^{\mathrm{x}+}\left(\mathrm{A}^{\mathrm{n}-}\right)_{\mathrm{x} / \mathrm{n}} \cdot \mathrm{mH}_{2} \mathrm{O}$, where $\mathrm{M}^{2+}, \mathrm{M}^{3+}$, and $\mathrm{A}^{\mathrm{n}-}$ represent the divalent, and trivalent metal ions, as well as an anion, respectively [14]. Despite the remarkable advantages of the pristine LDHs and metal oxides, their high energy cost demand, the low recoverability, and the fast electron-hole recombination confined their usage in the wastewater treatment methods [15]. Therefore, different researchers have combined the advantages of each photocatalyst by synthesizing different heterojunctions [16]. According to the literature review [17,18], the heterojunctions composed of a semiconductor (SC) with higher $\mathrm{CB}$ and VB position than those in other SC, can result in the type II heterojunction. It is widely believed that in the type II heterojunctions the photogenerated electrons of SC (I) can be accumulated on the CB of SC (II), and also the photogenerated holes can be gathered on SC (I) [19]. On the other hand, recently the step-scheme (S-scheme) heterojunctions have been nominated to possess a similar band structure with the type (II) heterojunction, but completely different photogenerated carrier transfer pathway [20]. In such kinds of heterojunctions, the useless photogenerated charge carriers recombine and the strong photogenerated electrons and holes remain in the $\mathrm{CB}$ of the reduction photocatalyst and $\mathrm{VB}$ of 
the oxidation semiconductor, respectively. For instance, Tao et. al. [21] have synthesized a Sscheme heterojunction of $\mathrm{MoS}_{2} / \mathrm{CoAl} \mathrm{LDH}$ which was able to induce more charge transfer and consequently high photodegradation performance.

So far, $\mathrm{LDHs}$ containing $\mathrm{Cu}$ or $\mathrm{Cr}$ have shown efficient catalytic activates due to providing specific structure. Considering the low recyclability, as well as the fast electron-hole recombination of the sole $\mathrm{LDH}$, we decided to integrate the merits of $\mathrm{Fe}_{3} \mathrm{O}_{4}$ and $\mathrm{CuCr}-\mathrm{LDH}$ to synthesize a novel magnetically separable nanocomposite which can be activated under visible-light irradiation. To the best of our knowledge, there is no report for the synthesis of a heterojunction of $\mathrm{Fe}_{3} \mathrm{O}_{4}$ and $\mathrm{CuCr}-\mathrm{LDH}$ nanoparticles to use in the photocatalytic activation of PMS. For the first principle scope of the present work, the $\mathrm{Fe}_{3} \mathrm{O}_{4} @ \mathrm{CuCr}-\mathrm{LDH}$ nanocomposite was synthesized and characterized. Thereafter, the activation of PMS was assessed in the presence of so-synthesized nanocomposite for the effective degradation of diethyl phthalate (DEP). The impact of main physicochemical parameters such as the catalyst concentration, the solution $\mathrm{pH}$, different light sources, and different concentrations of PMS was also studied. As the next step, the synergy factor of the Vis-light/composite/PMS process was investigated through the DEP and TOC removal. For further evaluation of the proposed degradation process in decreasing the toxicity of the target pollutant, some ecotoxicological tests were fulfilled using Lemna minor species. Finally, the S-scheme mechanism was thoroughly studied to give a deeper understanding of the high-performance S-scheme heterojunction photocatalyst.

\section{Experiments}

\subsection{Chemicals}

All the used chemicals were purchased from Sigma-Aldrich and used in the experiments without any further purification. 


\subsection{Synthesis of $\mathrm{Fe}_{3} \mathrm{O}_{4}, \mathrm{CuCr}-\mathrm{LDH}$, and $\mathrm{Fe}_{3} \mathrm{O}_{4} @ \mathrm{CuCr}-\mathrm{LDH}$}

$\mathrm{Fe}_{3} \mathrm{O}_{4}$ was synthesized with a method as described in the previously reported work [12]. Moreover, a facile co-precipitation method was used to prepare pure $\mathrm{CuCr}-\mathrm{LDH}$. To this end, $\mathrm{Cu}\left(\mathrm{NO}_{3}\right)_{2} \cdot 3 \mathrm{H}_{2} \mathrm{O}$ and $\mathrm{Cr}\left(\mathrm{NO}_{3}\right)_{3} \cdot 9 \mathrm{H}_{2} \mathrm{O}$ with the $\mathrm{Cu} / \mathrm{Cr}$ molar ratio of $2: 1$ were dissolved in 80 $\mathrm{mL}$ of deionized water to prepare Solution A. Afterward, $\mathrm{NaOH}(2 \mathrm{M})$ was provided in $20 \mathrm{~mL}$ of the deionized water as solution B. As the next step, solution A was titrated slowly by solution B under vigorously stirring until the solution $\mathrm{pH}$ closed to 9.5. Then, the achieved mixture was stirred continuously for $24 \mathrm{~h}$. The gained precipitation was collected after centrifuge, washed with water and ethanol, and finally transferred to the oven to be dried for $12 \mathrm{~h}$ under $60^{\circ} \mathrm{C}$.

$\mathrm{Fe}_{3} \mathrm{O}_{4} @ \mathrm{CuCr}-\mathrm{LDH}$ nanocomposite was also prepared with a co-precipitation method. In this context, three specific solutions were prepared as follows. Typically, $0.5 \mathrm{~g}$ of the sosynthesized $\mathrm{Fe}_{3} \mathrm{O}_{4}$ was dispersed in $150 \mathrm{~mL}$ of the water/methanol mixture $\left(\mathrm{V}_{\text {water }} / \mathrm{V}_{\text {methanol }}=\right.$ 1) for 15 min (solution A), followed by the dropwise addition of the same volume of $\mathrm{NaOH}(2$ M) prepared in the water/methanol mixture $\left(\mathrm{V}_{\text {water }} / \mathrm{V}_{\text {methanol }}=1\right)$ as solution $\mathrm{B}$. Thereafter, solution $\mathrm{C}$ was prepared with the addition of $(0.5 \mathrm{M}) \mathrm{Cu}\left(\mathrm{NO}_{3}\right)_{2} .3 \mathrm{H}_{2} \mathrm{O}$ and $(0.25 \mathrm{M})$ $\mathrm{Cr}\left(\mathrm{NO}_{3}\right)_{3} \cdot 9 \mathrm{H}_{2} \mathrm{O}$ in 100 and $50 \mathrm{~mL}$ of water/methanol mixture $\left(\mathrm{V}_{\text {water }} / \mathrm{V}_{\text {methanol }}=1\right)$, respectively. As the final step, solution $\mathrm{C}$ was dropped by drop added to the prepared mixture of solution A and B within 40 min and the solution was stirred for $24 \mathrm{~h}$ under continuous stirring at $60^{\circ} \mathrm{C}$. The obtained mixture was centrifuged and the resulted precipitation was washed and dried as like pure $\mathrm{CuCr}-\mathrm{LDH}$. It worth noting that all the solutions were prepared with the incorporation of Argon gas.

\subsection{Characterization of the catalysts}


The crystal phases of the synthesized nanomaterials were determined by X-ray diffraction (D8 Advance, Bruker, Germany) conducting at $45 \mathrm{kV}$ and $40 \mathrm{~mA}$, with an X-ray source of $\mathrm{Cu}$ $\mathrm{K} \alpha$ radiation $(\lambda=0.15406 \mathrm{~nm})$. The Fourier-transform infrared (FT-IR) analysis was carried out for the detection of the possible functional groups using a Tensor 27 spectrophotometer (Bruker, Germany) and a KBr disk method. The Brunauer-Emmett Teller (BET) method with a 3 Flex instrument (Micromeritics, USA) was applied to evaluate the surface area and the pore volume, from the recorded nitrogen absorption-desorption isotherms. Besides, the surface morphology, as well as the elemental mappings, were appraised using a scanning electron microscope (SEM, Tescan Mira3, Czech Republic) equipped with a Zeiss Sigma 300. A Hitachi H-7650 microscope operating at $80 \mathrm{kV}$, as well as a Hamamatsu AMT40 camera placed in a side position, was used to take the TEM images of the samples. Furthermore, an inductively coupled plasma emission spectroscopy (ICP-AES) using a Jobin-Yvon ULTIMA C instrument (USA) was applied for measuring the leaching concentrations of chromium, iron, and copper. Surface binding energy was measured by adopting X-ray photoelectron spectroscopy (XPS) analysis which was carried out with a hemispherical electron energy analyzer OMICRON EA125, Germany. All the recorded XPS spectrums were analyzed with an XPSPEAK software, Version 4.1. The Ultraviolet-visible diffuse reflectance spectrophotometry (UV-Vis DRS) with an Analytik Jena spectrophotometer (S 250, Germany) was used for measuring the bandgap of the as-prepared photocatalysts. The magnetic characterization of the synthesized samples was studied by a typical vibrating sample magnetometer (VSM, Lakeshore, 7400 Series). Furthermore, the produced hydroxyl radicals were detected by using a simple method using terephthalic acid (TA) as a probe [17]. Considering this method, nonfluorscence TA can react with ${ }^{\circ} \mathrm{OH}$ to produce 2hydroxyterephthalic acid which produces an emission peak at around $425 \mathrm{~nm}$ (under the excitation of $310 \mathrm{~nm})$. Therefore, in this work, $50 \mathrm{~mL}$ of TA solution $(0.5 \mathrm{mM})$ was prepared 
in the presence of $\mathrm{NaOH}(2 \mathrm{mM})$. Afterward, $1 \mathrm{~g} \mathrm{~L}^{-1}$ of the prepared catalysts were added to the solution, and then it was exposed to the visible-light irradiation under continuous stirring. Finally, at the predetermined time intervals, the samples were withdrawn and the concentration of 2-hydroxyterphthalic was tracked by a fluorescence spectrophotometer (Varian Cary Eclipse, USA).

\subsection{Photocatalytic experiments}

The degradation experiments were fulfilled in a $50 \mathrm{~mL}$ Pyrex cylindrical photocatalytic reactor using a solar simulator lamp (Ocean optics) as the source of the light for irradiation. To select the visible light irradiation, a cut-off filter $(\lambda \geq 420 \mathrm{~nm})$ was located before the reactor. The emission spectrum of the above-mentioned lamp was presented in Supplementary information (Fig S1). Water circulation was embedded around the reactor to maintain a constant temperature of around $293 \pm 2 \mathrm{~K}$. A predetermined amount of PMS and DEP (20 mg $\mathrm{L}^{-1}$ ) were added to a $50 \mathrm{~mL}$ reaction solution containing a certain concentration of catalysts. After adjusting the solution $\mathrm{pH}$ around 8 , it was transferred to the reactor. Before starting the photocatalytic degradation, the adsorption of DEP on the catalyst was assessed by stirring its solution in the dark for 2 hours. However, after 30 min of stirring no more adsorption of DEP was observed. Therefore, for each run, the solution was stirred for 30 min to reach the equilibrium of adsorption/desorption between the photocatalyst and DEP molecules. This stage was followed by 120 min of irradiation under continuous stirring. In each $15 \mathrm{~min}$ intervals, $3 \mathrm{~mL}$ of the suspension were regularly withdrawn from the reaction media, filtered by a syringe with a filter of $0.2 \mu \mathrm{m}$ (Macherey-Nagel, Germany), and finally transferred to a vial containing $1 \mathrm{~mL}$ of radical quencher (methanol). The residual DEP was analyzed by high-performance liquid chromatography (Alliance, waters, USA), using a C18 column $(2.1 \times 100 \mathrm{~mm}$ and particle size of $1.7 \mu \mathrm{m})$. An isocratic mode with a mobile phase consisted 
of $30 \%$ ultrapure water and $70 \%$ methanol at a flow rate of $0.8 \mathrm{~mL} \mathrm{~min}^{-1}$ was adopted for appropriate detection of DEP with a retention time of $8 \mathrm{~min}$. The corresponding degradation efficiency (DE) of DEP was calculated by considering the equation $\frac{C_{0}-C_{t}}{C_{0}} \times 100$ where $\mathrm{C}_{0}$ and $\mathrm{C}_{\mathrm{t}}$ are the initial and $\mathrm{t}(\mathrm{min})$ of DEP concentrations, respectively. Lastly, the Error bars representing \pm one standard deviation was reported from the mean of two measurements. The TOC analysis as well as the ecotoxicological assessment method have been precisely explained in the supplementary data. For the ecotoxicological studies, the Lemna minor species were collected from the Anzali Wetland in the North of Iran and cultivated by the described method in our previously published paper [22]. Also, the chlorophyll content was measured by the previously explained procedure [23]

\section{Results and discussion}

\subsection{Characterization}

The X-ray diffraction (XRD) method was used to study the crystal structure of the obtained nanocomposite, as presented in Fig. 1 (a). The results verified the existence of pure magnetite nanoparticles according to JCPDS card no. 01-089-0951. It is worth noting that the XRD pattern of the $\mathrm{Fe}_{3} \mathrm{O}_{4} @ \mathrm{CuCr}-\mathrm{LDH}$ nanocomposite showed the corresponding peaks of both magnetite and CuCr-LDH nanoparticles. The main XRD peaks of the CuCr-LDH nanoparticles obtained at $2 \theta$ values of $10.9,22,34$, and 60.5 indexing to the (003), (006), (012), and (110) reflections (JCPDS file no. 00-035-0965) indicate the layered structure with the hexagonal unit cells and the rhombohedral symmetry (space group $R-3 m$ ) [24]. Consequently, the results are good evidence for the existence of layered double hydroxide and magnetite in the final composite [24]. Although the intensity of the related peaks of $\mathrm{CuO}$ is lower than the specific peaks of $\mathrm{LDH}$, the main reason for the appearing impurity phases can be the outcome of poor controlling of $\mathrm{pH}$ and temperature in the course of the synthesis of 
layered double hydroxide [25].

The main functional group of the so-synthesized nanomaterials was ascertained by applying the FTIR analysis. The attained FT-IR spectrums of $\mathrm{Fe}_{3} \mathrm{O}_{4}, \mathrm{CuCr}-\mathrm{LDH}$, and $\mathrm{Fe}_{3} \mathrm{O}_{4} @ \mathrm{CuCr}-$ LDH nanocomposite are presented in Fig. 1 (b). The observed peaks below the $1000 \mathrm{~cm}^{-1}$ revealed the M-O-H bindings and M-O vibrations mainly Cu-O at 524, and $831 \mathrm{~cm}^{-1}$, Fe-O at 568 and $678 \mathrm{~cm}^{-1}$, and eventually $\mathrm{Cr}-\mathrm{O}$ at $610 \mathrm{~cm}^{-1}$ [26-28]. The absorption band that appeared at $1382 \mathrm{~cm}^{-1}$ in the FT-IR spectrums of the pure CuCr-LDH and $\mathrm{Fe}_{3} \mathrm{O}_{4} @ \mathrm{CuCr}-\mathrm{LDH}$ composite deduced the existence of intercalated $\mathrm{NO}_{3}{ }^{-}$anions [29]. Moreover, the peaks at 3451 and $1650 \mathrm{~cm}^{-1}$ correlate to the $\mathrm{O}-\mathrm{H}$ stretching vibration of the layered double hydroxide and the interlayer water molecules, respectively [30].

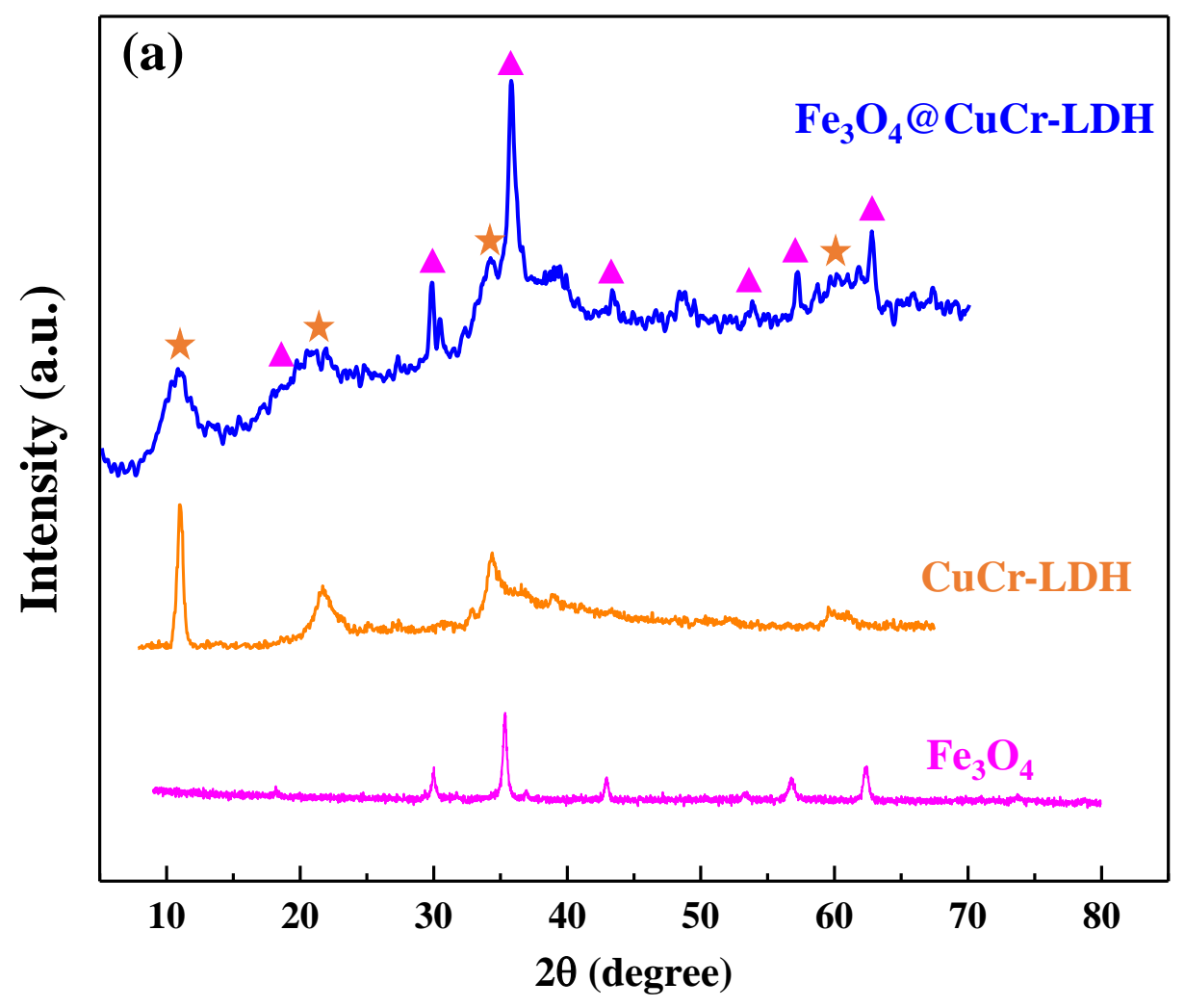




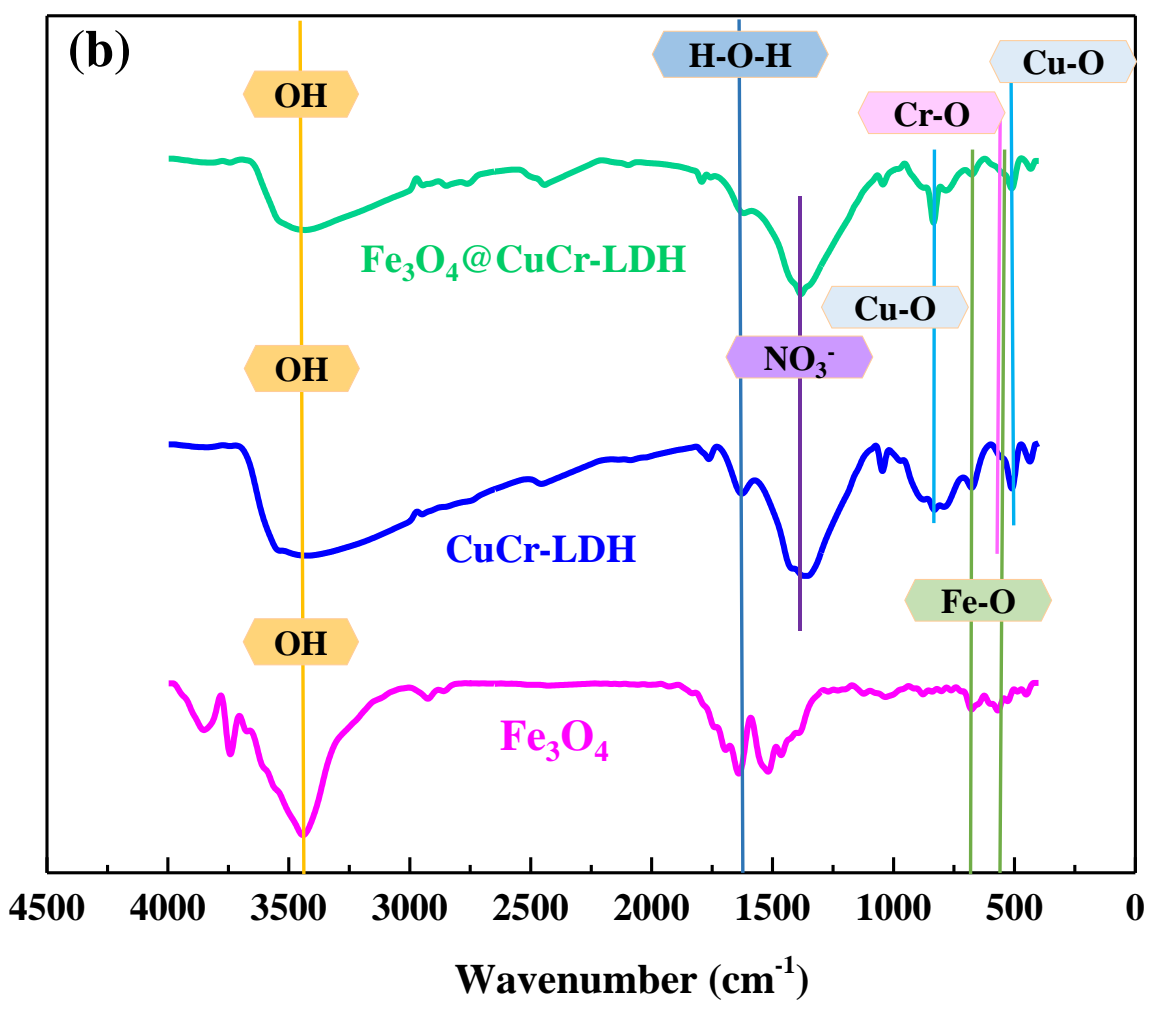

Fig. 1. (a) XRD pattern (b) FT-IR spectrum of the so-synthesized nanomaterials. 


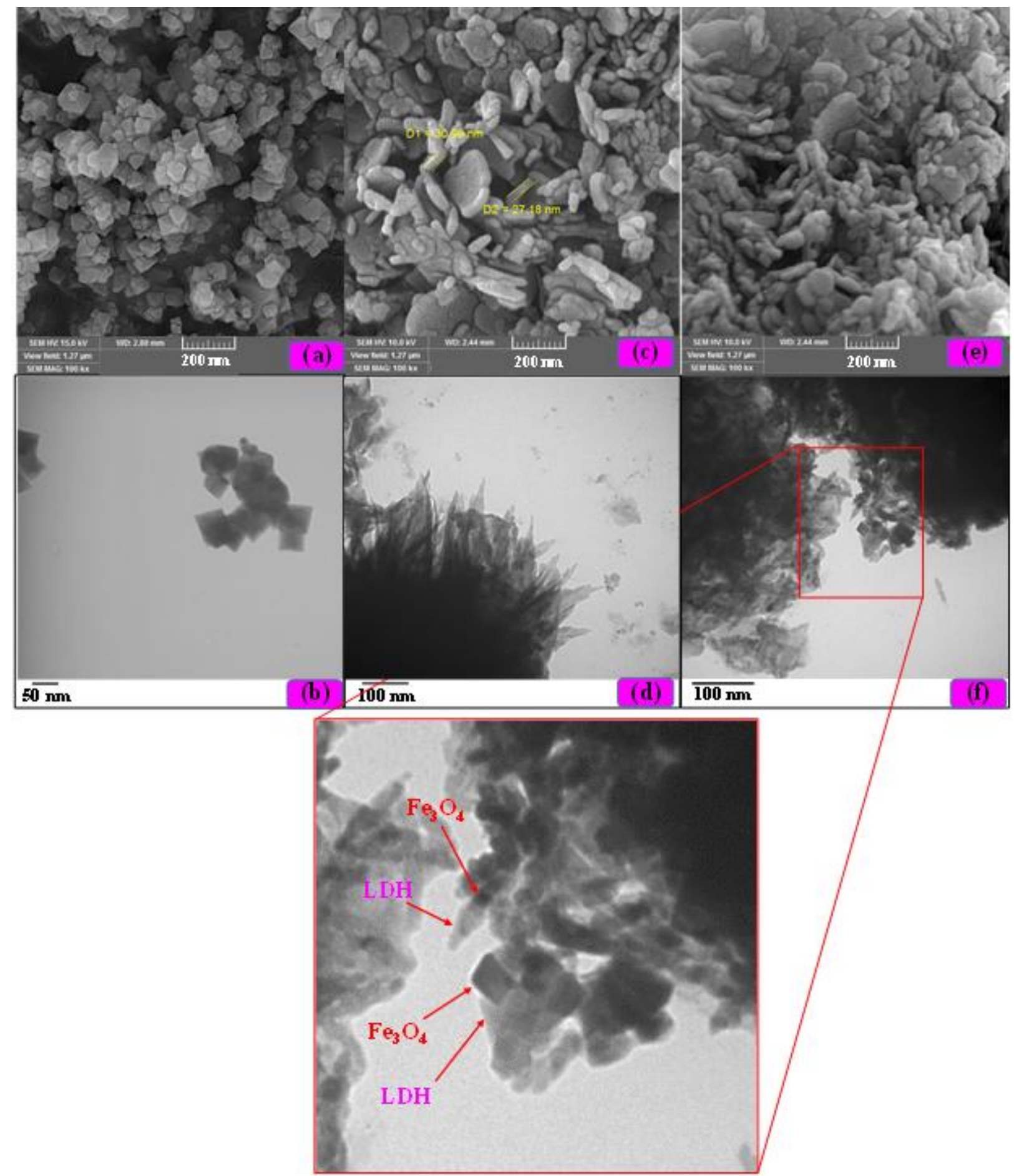

Fig. 2. The SEM and TEM images of (a and b) pure $\mathrm{Fe}_{3} \mathrm{O}_{4}$, (c and d) $\mathrm{CuCr}-\mathrm{LDH}$, and finally (e and f) $\mathrm{Fe}_{3} \mathrm{O}_{4} @ \mathrm{CuCr}-\mathrm{LDH}$ nanocomposite.

The SEM images of the so-synthesized $\mathrm{Fe}_{3} \mathrm{O}_{4}, \mathrm{CuCr}-\mathrm{LDH}$, and $\mathrm{Fe}_{3} \mathrm{O}_{4} @ \mathrm{CuCr}-\mathrm{LDH}$ nanocomposite were displayed in Fig. 2. As indicated in Fig. 2 (a) the pristine magnetite nanoparticles possess a cubic morphology. However, the SEM image of the pure CuCr-LDH 
depicts a lamellar structure that accords with the reported morphology for the other layered double hydroxides [31]. Fig. 2 (e) illustrates that CuCr-LDH nanosheets with an average thickness of 28-29 $\mathrm{nm}$ were uniformly distributed over the cubic magnetite nanoparticles, giving rise to the $\mathrm{Fe}_{3} \mathrm{O}_{4} @ \mathrm{CuCr}-\mathrm{LDH}$ nanocomposite. Besides, the attained TEM images had further confirmed the loading of lamellar $\mathrm{CuCr}-\mathrm{LDH}$ on the cubic magnetite nanoparticles. The TEM image of $\mathrm{Fe}_{3} \mathrm{O}_{4} @ \mathrm{CuCr}-\mathrm{LDH}$ composite which has been presented in Fig. 2 (f) proves the co-existence of magnetite nanoparticles with $\mathrm{CuCr}-\mathrm{LDH}$ nanosheets. Moreover, the Energy Dispersive X-ray (EDX) analysis was accomplished to a precise study of the semiquantitative elemental composition of pure magnetite, $\mathrm{CuCr}-\mathrm{LDH}$, and the resulted $\mathrm{Fe}_{3} \mathrm{O}_{4} @ \mathrm{CuCr}-\mathrm{LDH}$ nanocomposite. Fig. S2 shows that $\mathrm{Cu}, \mathrm{Cr}, \mathrm{Fe}$, and $\mathrm{O}$ elements were detected for the final nanocomposite, demonstrating the successful synthesis of $\mathrm{Fe}_{3} \mathrm{O}_{4} @ \mathrm{CuCr}-$ LDH nanocomposite. Nonetheless, the pure magnetite comprised of Fe, and O; whereas, the bare $\mathrm{CuCr}-\mathrm{LDH}$ demonstrated the existence of $\mathrm{Cu}, \mathrm{Cr}$, O, elements. Furthermore, sought to other analyses, the SEM mapping was carried out to demonstrate the elemental distribution of the elements on the surface of the nanocomposite, and the results were documented in Fig. S3. The results are good evidence for an appropriate and homogeneous distribution of the $\mathrm{Cu}, \mathrm{Cr}$, $\mathrm{Fe}$, and $\mathrm{O}$ elements throughout the whole structure of $\mathrm{Fe}_{3} \mathrm{O}_{4} @ \mathrm{CuCr}-\mathrm{LDH}$ nanocomposite. The bandgap energy of the prepared nanomaterials plays a remarkable role in their photocatalytic performance. Therefore, the bandgaps of as-synthesized nanomaterials were estimated by using Tauc's equation [22,28] . To this end, the $(\alpha h v)^{2}$ graph for photon energy was drawn and the bandgap values were reported by the tangent extrapolation with the $(\alpha h v)^{2}$ $=0$ (Fig. S4). Therefore, the calculated bandgap values were $3.25 \mathrm{eV}, 2.85 \mathrm{eV}$, and $1.72 \mathrm{eV}$, for $\mathrm{Fe}_{3} \mathrm{O}_{4}, \mathrm{CuCr}-\mathrm{LDH}$, and $\mathrm{Fe}_{3} \mathrm{O}_{4} @ \mathrm{CuCr}-\mathrm{LDH}$, respectively. Consequently, in comparison with the pure magnetite and $\mathrm{CuCr}-\mathrm{LDH}$, their composite has a smaller bandgap, which in turn results in its appropriate excitation under the visible light irradiation to form more electron- 
hole pairs and improve the photocatalytic activity under visible light [32].

To further explore the photocatalytic activity of the so-synthesized nanomaterials, their specific surface area and porosity were analyzed by applying the Brunauer-Emmett-Teller (BET) analysis. For this perspective, the $\mathrm{N}_{2}$ adsorption/desorption isotherms of the nanocatalysts at $77 \mathrm{~K}$ were recorded and summarized in Fig. S5. Taking into consideration the types of isotherms defined by the IUPAC classification, the samples manifested a type IV isotherm as the characterization of the mesoporous material [33]. Moreover, the total pore volume, the specific surface area of the pure magnetite, $\mathrm{LDH}$, and the composite were tabulated (Table. 1). Accordingly, the acquired BET surface area, and the total pore volume were raised for the composite $\left(80.6 \mathrm{~cm}^{2} \mathrm{~g}^{-1}, 0.32 \mathrm{~cm}^{3} \mathrm{~g}^{-1}\right)$.

Table 1. The Brunauer-Emmett-Teller surface areas and pore-volume were gained from the BET analysis.

\begin{tabular}{lcc}
\hline Samples & Surface area $\left(\mathbf{m}^{2} \mathbf{g}^{-}\right.$ & Pore volume $\left(\mathbf{c m}^{3} \mathbf{g}^{-\mathbf{1}}\right)$ \\
& $\left.{ }^{\mathbf{1}}\right)$ & \\
\hline $\mathrm{Fe}_{3} \mathrm{O}_{4}$ & 7.85 & 0.12 \\
\hline $\mathrm{CuCr}-\mathrm{LDH}$ & 50.69 & 0.20 \\
\hline $\mathrm{Fe}_{3} \mathrm{O}_{4} @ \mathrm{CuCr}-$ & 80.60 & 0.32 \\
$\mathrm{LDH}$ & & \\
\hline
\end{tabular}

Given the magnetic properties of the photocatalysts in which were $\mathrm{Fe}_{3} \mathrm{O}_{4}$, these materials have attracted the attention of scientists. Herein, the magnetic behavior of the $\mathrm{Fe}_{3} \mathrm{O}_{4}$ was evaluated after its composition with the CuCr-LDH nanosheets. Therefore, the magnetic measurement of the fresh $\mathrm{Fe}_{3} \mathrm{O}_{4}$ and the $\mathrm{Fe}_{3} \mathrm{O}_{4} @ \mathrm{CuCr}-\mathrm{LDH}$ composite was carried out by the VSM analysis. According to Fig. S6 and the results reported in Table 2 the magnetization 
saturation values $(\mathrm{Ms})$ of $\mathrm{Fe}_{3} \mathrm{O}_{4}$ and $\mathrm{Fe}_{3} \mathrm{O}_{4} @ \mathrm{CuCr}-\mathrm{LDH}$ composite were 77 and 59, respectively. Therefore, the results evidenced the high magnetic property of the prepared samples which was further confirmed by placing a magnet near the solution of the solution containing composite (Fig. S6 (b)). As it is clear, the placed magnet attracted the particles toward itself after a few seconds, depicting the magnetic properties of the composite.

Table 2. Magnetic characterization of $\mathrm{Fe}_{3} \mathrm{O}_{4}$ and $\mathrm{Fe}_{3} \mathrm{O}_{4} @ \mathrm{CuCr}-\mathrm{LDH}$.

\begin{tabular}{lccc}
\hline Samples & ${ }^{1} \mathbf{M}_{\mathbf{s}}\left(\mathbf{e m u} \mathbf{g}^{-}\right.$ & $\mathbf{S Q R}$ & ${ }^{3} \mathbf{H}_{\mathbf{c}}$ \\
& $\left.\mathbf{1}^{\mathbf{1}}\right)$ & $\left({ }^{2} \mathbf{M}_{\mathbf{r}} / \mathbf{M}_{\mathbf{s}}\right)$ & $(\mathbf{G})$ \\
\hline $\mathrm{Fe}_{3} \mathrm{O}_{4}$ & 77 & 0.22 & 191 \\
\hline $\mathrm{Fe}_{3} \mathrm{O}_{4} @ \mathrm{CuCr}-$ & 59 & 0.16 & 195 \\
$\mathrm{LDH}$ & & & \\
\hline $\mathrm{M}_{\mathrm{s}}$ (saturation magnetization), $\mathrm{M}_{\mathrm{r}}$ (remnant magnetization), $\mathrm{H}_{\mathrm{c}}$ (coercivity)
\end{tabular}

XPS analysis was performed for the determination of the chemical state, and the elemental composition of the sample surface and the achieved spectra were presented in Fig.S7. The full survey XPS spectrum of $\mathrm{Fe}_{3} \mathrm{O}_{4} @ \mathrm{CuCr}-\mathrm{LDH}$ displayed in Fig. S7 proves the existence of all constituent elements such as $\mathrm{Cu}, \mathrm{Cr}, \mathrm{Fe}$, and $\mathrm{O}$ in the ultimate $\mathrm{Fe}_{3} \mathrm{O}_{4} @ \mathrm{CuCr}-\mathrm{LDH}$ nanocomposite. Likewise, the deconvoluted peaks at $\mathrm{Cu} 2 \mathrm{p}$ were also presented in Fig. S6. Given that, $\mathrm{Cu}^{2+}$ was recognized by the emergence of the distinct peaks at the binding energies of 960.59, 951.9, 941.36, and $933 \mathrm{eV}$. In this context, the peaks at $951.9 \mathrm{eV}$ and 933 $\mathrm{eV}$ verify the $\mathrm{Cu} 2 \mathrm{p}_{1 / 2}$ and $\mathrm{Cu} 2 \mathrm{p}_{3 / 2}$ signals, respectively [34-36]. On the other hand, the attendance of $\mathrm{Cr}^{3+}$ was studied through the ascribed fine spectra $\mathrm{Cr} 2 \mathrm{p}$. The peaks settled at 577.38 affirmed $\mathrm{Cr} 2 \mathrm{P}_{3 / 2}$ state; whereas, the $\mathrm{Cr} 2 \mathrm{p}_{1 / 2}$ state was confirmed with the appeared peak at 587.1 eV [36,37]. Lastly, the recorded high-resolution Fe 2p spectrum implied the presence of $\mathrm{Fe}^{2+}$ and $\mathrm{Fe}^{3+}$ on the surface of the sample by observing two main peaks with their 
satellite peaks located at the binding energy of 705-735 [38].

\subsection{Photocatalytic activity of prepared nanomaterials}

In Fig. S8, the photocatalytic activity of the synthesized pristine $\mathrm{CuCr}-\mathrm{LDH}, \mathrm{Fe}_{3} \mathrm{O}_{4}$, and $\mathrm{Fe}_{3} \mathrm{O}_{4} @ \mathrm{CuCr}-\mathrm{LDH}$ nanocomposite was appraised for the degradation of DEP in the presence of visible light irradiation. According to the results, the adsorption and the degradation efficiency (DE) of DEP upon the visible light irradiation ascent in the series of $\mathrm{Fe}_{3} \mathrm{O}_{4} @ \mathrm{CuCr}$ $\mathrm{LDH}>\mathrm{CuCr}-\mathrm{LDH}>\mathrm{Fe}_{3} \mathrm{O}_{4}$. However, among them, the degradation performance of the $\mathrm{Fe}_{3} \mathrm{O}_{4} @ \mathrm{CuCr}-\mathrm{LDH}$ nanocomposite was higher compared with its adsorption ability. According to the results gained from the DRS results (Fig. S3), the integration of CuCr-LDH and $\mathrm{Fe}_{3} \mathrm{O}_{4}$ boosted their photocatalytic activity by increasing the visible light absorption of the composite. Consequently, the $\mathrm{Fe}_{3} \mathrm{O}_{4} @ \mathrm{CuCr}-\mathrm{LDH}$ composite was adopted as an appropriate photocatalyst for further experiments. It worth noting that our results are in good agreement with the results obtained by Sea Jin et. al. [39]. They have tried to study the degradation efficiency of DEP by using a widely used $\mathrm{TiO}_{2}$, as well as tungsten oxide doped $\mathrm{TiO}_{2}$. According to their results, loading $\mathrm{WO}_{3}$ onto the pristine $\mathrm{TiO}_{2}$ has improved the degradation efficiency of DEP under visible light.

\subsection{Influence of operational parameters}

\subsubsection{Impact of photocatalyst concentration}

Fig. 3 illustrates the impact of the catalyst concentration of $0.5-2 \mathrm{~g} \mathrm{~L}^{-1}$ on the effective degradation of DEP with respect to the degradation efficiency (DE) at different intervals of time. The results suggest that the increase in the photocatalyst concentration from 0.5 to $1 \mathrm{~g} \mathrm{~L}^{-}$

${ }^{1}$ has a positive effect on achieving the higher degradation efficiency, wherein, the DE of DEP enhances from $40 \%$ to $70 \%$. Indeed, compared with the lower catalyst concentration, the 
increase in the catalyst dose could compensate for the impoverished amount of active sites and surface area [22]. Nevertheless, the increasing catalyst concentration from $1 \mathrm{~g} \mathrm{~L}^{-1}$ to $2 \mathrm{~g} \mathrm{~L}^{-}$ ${ }^{1}$ resulted in the reverse effect and showed a drop in the DE of DEP during 150 min of irradiation. On the other hand, during $30 \mathrm{~min}$ of the process and in the absence of light the DEP removal was gradually increased by the increment of the catalyst concentration up to $2 \mathrm{~g}$ $\mathrm{L}^{-1}$. These results provide appropriate evidence that the higher amount of catalyst displayed the principal effect on the degradation of DEP under the visible light irradiation, and the main reason for this phenomenon can be interpreted to the lower penetration of the visible light due to the higher turbidity in the solution [22]. Finally, considering all the aspects, the catalyst concentration of $1 \mathrm{~g} \mathrm{~L}^{-1}$ was reported as the optimum value for the other experiments.

\subsubsection{The effect of initial pH}

It is well-known that the initial $\mathrm{pH}$ can influence the performance of different advanced oxidation processes [5]. Therefore, a set of experiments were fulfilled in this regard and the results were exhibited in Fig. 3. As clear from the figure, under the visible light irradiation, a clear alteration of DE was observed. The activity of the Vis-light/Composite/PMS process for the degradation of DEP was enhanced by increasing the solution $\mathrm{pH}$ from 3 to 8 and finally followed with an obvious drop for the $\mathrm{pH}$ value of 10 and 12 .

Furthermore, the obtained $\mathrm{pH}_{\mathrm{pzc}}$ for the $\mathrm{Fe}_{3} \mathrm{O}_{4} @ \mathrm{CuCr}-\mathrm{LDH}$ nanocomposite was found to be 8.9 , which reveals that the surface of the composite possesses a positive charge in the acidic and neutral solution. Considering the $\mathrm{pK}_{\mathrm{a}}$ of PMS which is reported to be $9.4, \mathrm{HSO}_{5}{ }^{-}$is a more stable ion than the ionic form $\left(\mathrm{SO}_{5}{ }^{2-}\right)$. Owing to the occurrence of the hydrogen bonds between the O-O group of $\mathrm{HSO}_{5}{ }^{-}$and the available $\mathrm{H}^{+}$in the acidic solution [40], the attachment of the $\mathrm{H}^{+}$to the $\mathrm{HSO}_{5}{ }^{-}$species can inhibit its approach to the positively charged surface of $\mathrm{Fe}_{3} \mathrm{O}_{4} @ \mathrm{CuCr}-\mathrm{LDH}$. Therefore, the declined DEP degradation efficiency in the 
lower $\mathrm{pH}$ value can be attributed to the descended participation of $\mathrm{HSO}_{5}{ }^{-}$in the activation process which can result in the reduced yield of reactive $\mathrm{SO}_{4}{ }^{--}$[41]. On the other hand, in the case of higher $\mathrm{pH}$ values, the drop in the DE of DEP relates to the PMS tendency to be decomposed to $\mathrm{SO}_{5}{ }^{2-}$ [42]. Further reaction of PMS with the produced $\mathrm{SO}_{5}{ }^{2-}$ can result in the production of singlet oxygen. However, from the reactivity point of view, the singlet oxygen has a lower oxidizing potential in comparison with hydroxyl and sulfate radicals [43].

To avoid the formation of metal hydrated and hydroxide species in acidic and basic condition [44], respectively, and not to use the chemicals for adjusting the $\mathrm{pH}$ of the solution, a pH value of 8 with the higher DE of DEP was selected to be as the optimum value for the further reactions.

\subsubsection{Impact of PMS concentration}

The main dependency of the DEP degradation to the PMS concentration was investigated and the results were presented in Fig. 3. Overall, the attained results for the Vislight/Composite/PMS process affirm that the DE of DEP enhances by the synchronic rising in the PMS concentration from 1 to $14 \mathrm{mM}$. The principal reason for the obtained results can be attributed to the promoted degradation of DEP due to the formation of a higher amount of reactive $\mathrm{SO}_{4}{ }^{--}$species in the presence of more PMS. Notwithstanding, a slight difference in DE of DEP was observed in the presence of 8 and $14 \mathrm{mM}$ of PMS. As these results well accord with the obtained results in the previous studies [45], by enhancing the PMS concentration to $14 \mathrm{mM}$, the restrained amount of $\mathrm{F}_{3} \mathrm{O}_{4} @ \mathrm{CuCr}-\mathrm{LDH}$ for the activation of PMS and the self-quenching reaction aroused between the extra amount of $\mathrm{HSO}_{5}{ }^{-}$and the available $\mathrm{SO}_{4}{ }^{--}$can decline the DE $[46,47]$. For further investigation, the obtained results were compared with the direct oxidation of the DEP by $8 \mathrm{mM}$ of PMS as well as the sole 
photocatalytic degradation in the absence of PMS as the control reactions. Consequently, only $8 \mathrm{mM}$ of the PMS or the sole photocatalytic degradation is insufficient for the effective degradation of DEP; whereas, their integration led to the proper activation of PMS and finally higher degradation of DEP.

\subsubsection{Impact of the light source}

According to the photoactivity of PMS and the prepared photocatalyst, the effect of different light sources was evaluated for different processes such as photolysis (just light), photocatalytic (light/composite), and activated PMS with just light (light/ PMS) or both the composite and PMS with light (light/composite/PMS) (Fig. 3). From the figure, it can be concluded that photolysis resulted in negligible DEP degradation efficiency even in the case of using UVA-light. However, in comparison with Vis-light, UVA-light illustrated an efficient PMS activation performance to result in the enhanced DEP degradation efficiency [48]. Considering the DRS analysis, it was found that $\mathrm{Fe}_{3} \mathrm{O}_{4} @ \mathrm{CuCr}-\mathrm{LDH}$ was a visible lightresponsive photocatalyst; in consequence, its activity was assessed under different light conditions and in the absence of PMS. Despite obtaining 59\% of the DEP degradation efficiency in the presence of UVA-light, the so-synthesized catalyst resulted in $28 \%$ of degradation efficiency for DEP under the visible light irradiation. On the other hand, it was found out that with the combination of so-synthesized nanocomposite and PMS, a further amount of DEP was degraded under all light conditions. Taking account of the reactions (1) to (6) $[46,49,50]$, these findings can mainly be related to the photocatalytic activity of the sosynthesized composite which in turn can enhance the activation of PMS to produce different radical species and subsequently attack the DEP molecules.

$$
\text { Composite }+\mathrm{h} v \rightarrow \mathrm{e}^{-}+\mathrm{h}^{+}
$$

$\mathrm{O}_{2}+\mathrm{e}^{-} \rightarrow \mathrm{O}_{2}^{-}$ 
$417 \quad \mathrm{HSO}_{5}^{-}+\mathrm{e}^{-} \rightarrow \mathrm{SO}_{4}^{2-}+{ }^{\bullet} \mathrm{OH}$

$418 \quad \mathrm{HSO}_{5}^{-}+\mathrm{e}^{-} \rightarrow \mathrm{SO}_{4}^{\cdot-}+\mathrm{OH}^{-}$

$419 \quad \mathrm{HSO}_{5}^{-}+\mathrm{h}^{+} \rightarrow \mathrm{SO}_{5}^{\cdot-}+\mathrm{H}^{+}$

$420 \quad 2 \mathrm{SO}_{5}^{\cdot-} \rightarrow 2 \mathrm{SO}_{4}^{\cdot-}+\mathrm{O}_{2}$

As the degradation efficiency for DEP was still high (70\%) in the case of using Vis-

light/Composite/PMS, the degradation process has occurred under the visible light source $(\lambda \geq$ $420 \mathrm{~nm}$ ) was adopted for further DEP degradation study.
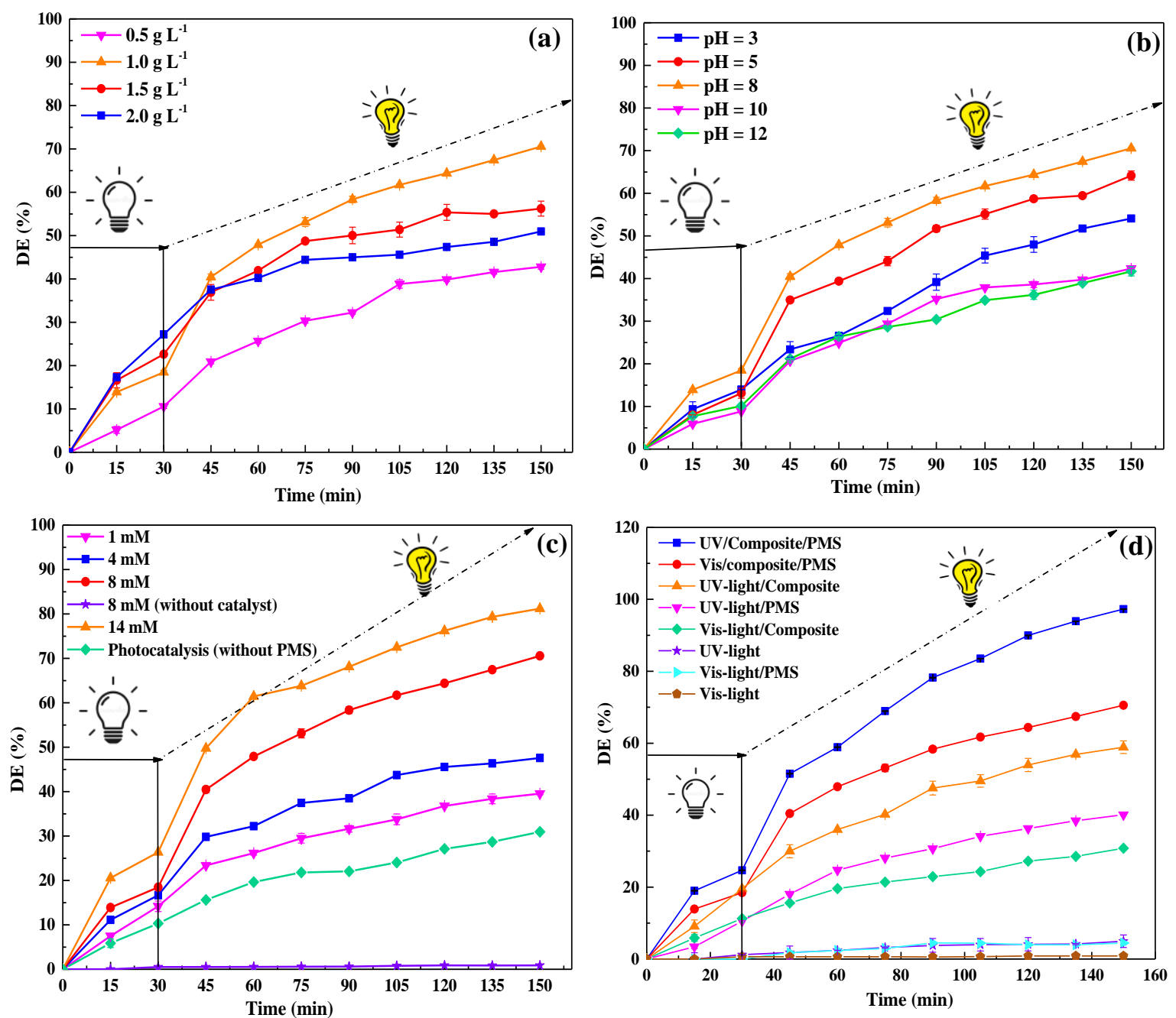

Fig. 3. Impact of the (a) photocatalyst concentration, (b) initial pH, (c) PMS concentration, 
and different light conditions on the DE of the DEP. Experimental conditions: $[\mathrm{DEP}]=20 \mathrm{mg}$ $\mathrm{L}^{-1}$, catalyst concentration of $1 \mathrm{~g} \mathrm{~L}^{-1},[\mathrm{PMS}]=8 \mathrm{mM}$, and $\mathrm{pH}=8$.

\subsection{Synergistic effect of the optimum process}

Diverse processes such as photolysis, adsorption, direct oxidation, photocatalytic degradation, and activated PMS by visible-light, sole composite, and visible-light/composite were evaluated for the removal of DEP and the results were reported in Fig. 4. It is evident from the results that direct photolysis and oxidation processes showed negligible degradation efficiency of DEP. On the other hand, according to the literature review, PMS cannot be activated by visible light irradiation [50]; therefore, its performance in the proper degradation of DEP was negligible. According to Fig. 4, 10 \% of DEP was adsorbed on the $\mathrm{Fe}_{3} \mathrm{O}_{4} @ \mathrm{CuCr}$ $\mathrm{LDH}$ and it was preserved until $120 \mathrm{~min}$ of the reaction time. However, the direct photocatalytic degradation of DEP under visible light irradiation resulted in approximately $30 \%$ of DE. Finally, it can be concluded from Fig. 4 that the activation of PMS in the presence of Vis-light and composite was the effective process for the degradation of DEP. 


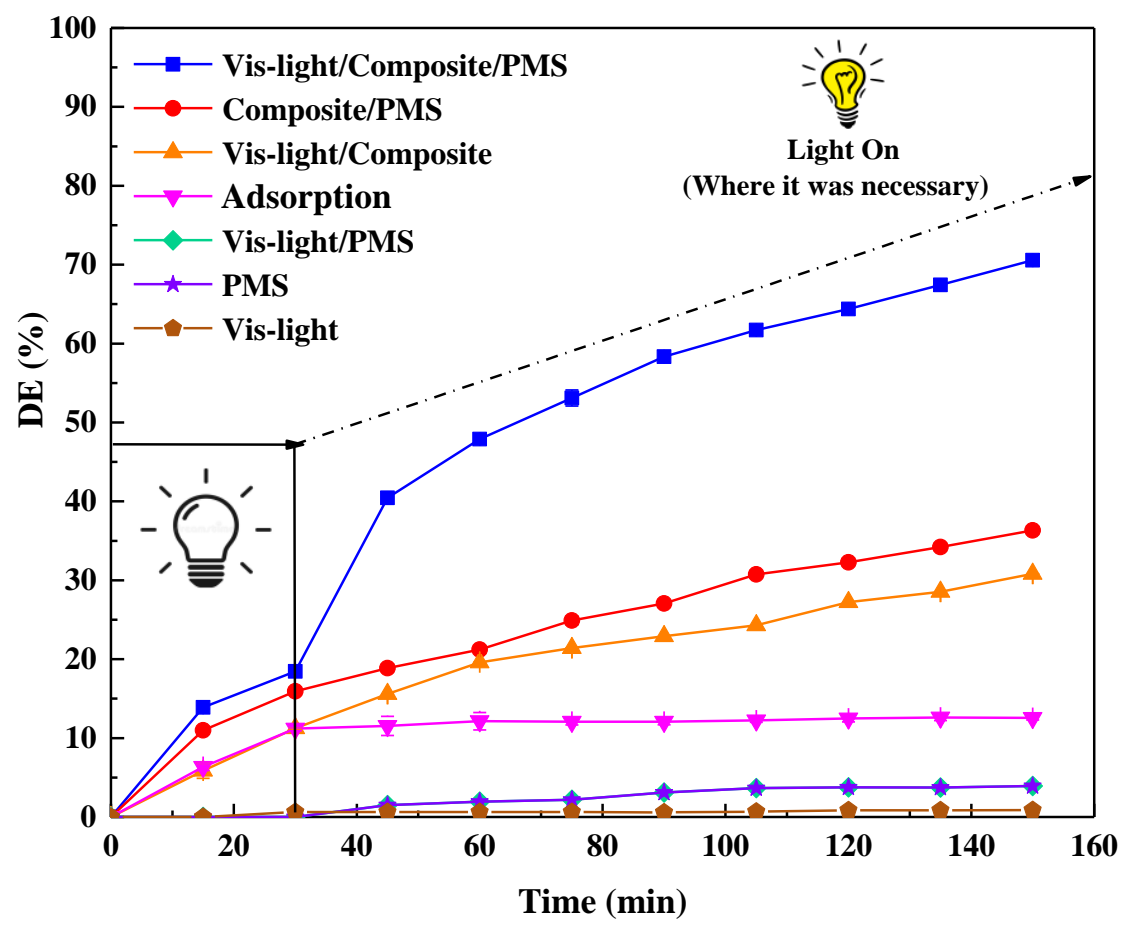

Fig. 4. The effect of different processes on the degradation of DEP. Experimental conditions: catalyst concentration of $1 \mathrm{~g} \mathrm{~L}^{-1},[\mathrm{DEP}]=20 \mathrm{mg} \mathrm{L}^{-1},[\mathrm{PMS}]=8 \mathrm{mM}$ and $\mathrm{pH}=8$.

Herein, the synergistic effect of the optimal process was evaluated to clarify the efficient impact of integrating the Vis-light and composite for the activation of PMS. To this end, the pseudo-first-order kinetic model [35] was used and the corresponding rate constants $\left(\mathrm{k}_{\mathrm{app}}\right)$ were reported for each of the processes. The $\mathrm{k}_{\mathrm{app}}$ as well as the correlation coefficient were inserted in Fig. S9. As it is clear form Fig. 4, the sole Vis-light and PMS showed negligible effect on the degradation of DEP. Moreover, during 30 min of dark condition the adsorption was equilibrated and no more adsorption was observed after $30 \mathrm{~min}$. Therefore, the obtained $\mathrm{K}_{\text {app }}$ for the sole PMS $\left(\mathrm{K}_{\mathrm{PMS}}=0.0003 \mathrm{M}^{-1} \mathrm{~min}^{-1}, \mathrm{R}^{2}=0.95\right)$, Vis-light $\left(\mathrm{K}_{\text {Vis-light }}=0.0001 \mathrm{M}^{-1}\right.$ $\left.\min ^{-1}, \mathrm{R}^{2}=0.96\right)$ and adsorption $\left(\mathrm{K}_{\text {composite }}=0.0001 \mathrm{M}^{-1} \min ^{-1}, \mathrm{R}^{2}=0.95\right)$ was negligible and they were not inserted in Fig. S9. The results revealed that the correlation coefficient $\left(\mathrm{R}^{2}\right)$ values for the pseudo-first-order model were higher than 0.95 . Therefore, it can be deduced that the degradation rates related to all the applied processes followed the pseudo-first-order 
kinetic.

The higher $\mathrm{k}_{\text {app }}$ of the Vis-light/composite/PMS system from those of the others revealed the efficient activation of PMS with the assistance of composite and visible light. For further studying, we used the attained $k_{\text {app }}$ for the calculation of the synergy factor for different methods of PMS activation. Accordingly, by applying the following equations [22,51] the synergy factors of PMS/Vis-light, PMS/composite, and PMS/Vis-light/composite processes were determined to be $0.1,8$, and 14 , respectively.

$$
\text { Synergy factor } \quad=\frac{\mathrm{K}_{\mathrm{PMS} / \text { vis-light }}}{\mathrm{K}_{\mathrm{PMS}}+\mathrm{K}_{\text {Vis-light }}}
$$

$$
\text { Synergy factor }{ }_{\mathrm{PMS} / \text { composite }}=\frac{\mathrm{K}_{\mathrm{PMS} / \text { composite }}}{\mathrm{K}_{\mathrm{PMS}}+\mathrm{K}_{\text {composite }}}
$$

$$
\underset{\text { SMnergy factor }}{\text { PMS/composite/Vis-light }}=\frac{\mathrm{K}_{\text {PMS/composite/Vis-light }}}{\mathrm{K}_{\mathrm{PMS}}+\mathrm{K}_{\text {composite }} \mathrm{K}_{\text {Vis-light }}}
$$

Different researches have been done for the activation of PMS in the presence of light irradiation and heterogeneous catalysts. For instance, Golshan et.al. [52] studied the effect of a widely used $\mathrm{TiO}_{2}$ and $\mathrm{CuFe}_{2} \mathrm{O}_{4}$ and their composite for the activation of PMS. According to their results, the integration of UV and $\mathrm{TiO}_{2} @ \mathrm{CuFe}_{2} \mathrm{O}_{4}$ composite enhanced the activation of PMS. Therefore, the degradation performance of the $\mathrm{UV} / \mathrm{TiO}_{2} @ \mathrm{CuFe}_{2} \mathrm{O}_{4} / \mathrm{PMS}$ process has been enhanced two times more in comparison with the individual $\mathrm{TiO}_{2} @ \mathrm{CuFe}_{2} \mathrm{O}_{4} / \mathrm{PMS}$ and UV/PMS processes. However, in our work the synergy factor of 14 of PMS/Vislight/composite demonstrated the efficient activation of PMS in the presence of visible light and composite. The principal reason can be associated with the effectual activation of PMS in the presence of the photocatalyst under the visible light irradiation [46] (reactions (1) to (6)). It worth noting that according to the reactions (7) to (13), the presence of transition metals in the so-synthesized photocatalysts can accelerate the PMS activation to the $\mathrm{SO}_{4}{ }^{--}[41,53]$.

$$
\equiv \mathrm{Fe}^{(\mathrm{II})}+\mathrm{HSO}_{5}^{-} \rightarrow \equiv \mathrm{Fe}^{(\mathrm{III})}+\mathrm{SO}_{4}^{--}+\mathrm{OH}^{-}
$$




$$
\begin{aligned}
& \equiv \mathrm{Cu}^{(\mathrm{II})}+\mathrm{HSO}_{5}^{-} \rightarrow \equiv \mathrm{Cu}^{(\mathrm{I})}+\mathrm{SO}_{5}^{\cdot-}+\mathrm{H}^{+} \\
& \equiv \mathrm{Cu}^{(\mathrm{I})}+\mathrm{HSO}_{5}^{-} \rightarrow \equiv \mathrm{Cu}^{(\mathrm{II})}+\mathrm{SO}_{4}^{\cdot-}+\mathrm{OH}^{-} \\
& \equiv \mathrm{Cr}^{(\mathrm{III})}+\mathrm{e}^{-} \rightarrow \equiv \mathrm{Cr}^{(\mathrm{II})} \\
& \equiv \mathrm{Cr}^{(\mathrm{II})}+\mathrm{HSO}_{5}^{-} \rightarrow \equiv \mathrm{Cr}^{(\mathrm{III})}+\mathrm{SO}_{4}^{\cdot-}+\mathrm{OH}^{-} \\
& \mathrm{SO}_{4}^{\cdot-}+\mathrm{H}_{2} \mathrm{O} \rightarrow \mathrm{H}^{+}+\mathrm{SO}_{4}^{2-}+\cdot \mathrm{OH} \\
& \mathrm{SO}_{4}^{\cdot-} / \cdot \mathrm{OH}+\mathrm{DEP} \rightarrow \mathrm{products}^{-}
\end{aligned}
$$

\subsection{Toxicity assessment and TOC removal}

According to the literature review [22], in the course of photocatalytic degradation, the target pollutants can be broken into smaller products which have been reported to be more toxic than the parent compounds [54]. Therefore, the ecotoxicological tests were fulfilled to under the optimum operational parameters to assess the biological responses of the living organisms to the photocatalytically treated or untreated DEP solution using the Vis-light/composite/PMS process. Lemna minor species as the aquatic plants are sensitive to a wide range of water pollutants; therefore, they were used for the toxicity assessment of the target pollutant and the produced by-products. After exposing the Lemna minor fronds were exposed with the control solution of untreated DEP and treated DEP solution for 60 and 120 min the visual changes of the fronds were monitored and reported in Fig. S10. The images which have been taken after 8 days showed that the toxicity of the DEP solution was decreased with increasing the degradation time up to $120 \mathrm{~min}$. Moreover, the fronds of Lemna minor species kept their growth rate after $120 \mathrm{~min}$ of the degradation process. Furthermore, the total chlorophyll content of the fronds exposed to 60 and 120 min of degradation process has been presented in Fig. S10. It is obvious that the chlorophyll content increased after $60 \mathrm{~min}$ and $120 \mathrm{~min}$ of process. These findings can be interpreted as the ability of the proposed optimum degradation 
system for the breaking the DEP molecules to the less or nontoxic compounds. It worth noting that our results are in good accordance with the literature reports [23].

Moreover, the mineralization of DEP was evaluated under applying diverse degradation processes such as Vis-light/composite/PMS, UV-light/composite/PMS, and sole UV or Vislight. Fig. S11 shows the TOC decrease as a function of irradiation time in the presence of the so-synthesized composite while holding all other operational parameters the same. The results were good evidence that the sole photolysis with the UVA or Vis-light did not affect the TOC decrease (the results were not shown). However, it can be observed that after $45 \mathrm{~h}$ of UV irradiation, $\mathrm{Fe}_{3} \mathrm{O}_{4} @ \mathrm{CuCr}-\mathrm{LDH}$ composite had an overall TOC removal of 74\%; whereas, it was found to be $50 \%$ under the Vis-light irradiation. This can be interpreted by the higher activation of PMS under UVA irradiation [48].

\subsection{Photocatalytic mechanism}

To probe the contribution of principle ROS accounting for the effective degradation of DEP, some quenching tests were done. In this context, different radical scavengers such as tert-butyl alcohol (TBA) [22], isopropyl alcohol (IPA) [53], Benzoquinone (BQ) [22], and EDTA [55] were used as the appropriate inhibitors of ${ }^{\circ} \mathrm{OH}, \mathrm{SO}_{4}{ }^{-{ }^{-}}, \mathrm{O}_{2}{ }^{--}$, and $\mathrm{h}^{+}$, respectively. According to the results presented in Fig. 5, under the optimal conditions, and in the absence of the scavengers, $70 \%$ of the DEP was degraded. However, the influence of the radical scavenging agents on the performance of the DEP degradation followed the order of IPA $>$ TBA $>$ EDTA>BQ affirming the predominant contribution of $\mathrm{SO}_{4}{ }^{-}$and ${ }^{\circ} \mathrm{OH}(22.8 \%$ and $18.1 \%$ respectively). According to the inserted figure in Fig. 5, the contribution of $\mathrm{h}^{+}$and $\mathrm{O}_{2}{ }^{-}$was also confirmed by adding EDTA and $\mathrm{BQ}$. Therefore, the results prove that the photogenerated $\mathrm{e}^{-}$and $\mathrm{h}^{+}$on the prepared composite have an adequate reduction and oxidation potential for generating $\mathrm{O}_{2}{ }^{--}$and ${ }^{\circ} \mathrm{OH}$. 


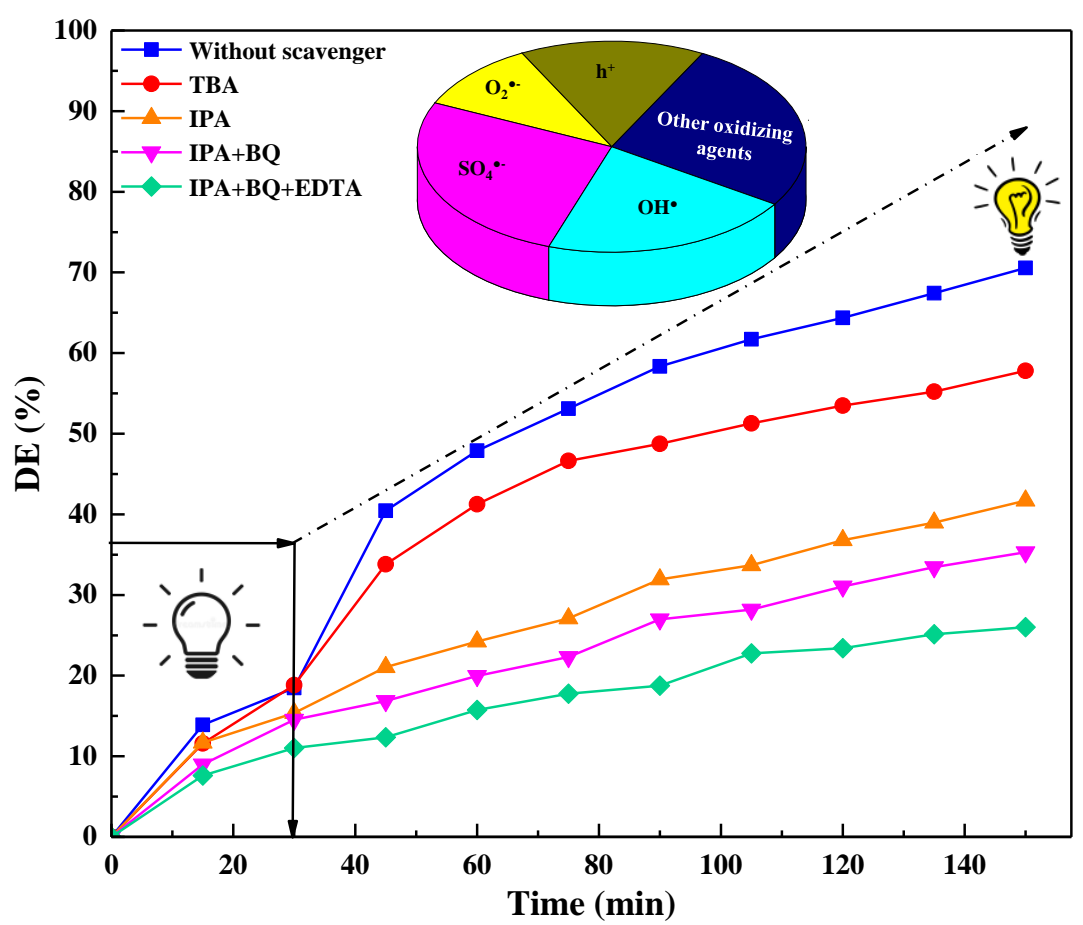

Fig. 5. The effect of different scavengers on the DEP degradation. Experimental conditions: catalyst concentration of $1 \mathrm{~g} \mathrm{~L}^{-1}$, $[\mathrm{DEP}]=20 \mathrm{mg} \mathrm{L}^{-1}$, $[\mathrm{PMS}]=8 \mathrm{mM}, \mathrm{pH}=8$ and molar ratio of scavenger vs. $\mathrm{DEP}=10: 1$. s.

A set of experiments were done to deeply investigate the type of the prepared heterojunction and define the separation and transfer pathway of the charge carriers between the semiconductors. In this regard, the $\mathrm{CB}$ and $\mathrm{VB}$ of the semiconductors were determined by using XPS valance band spectra [17]. Therefore, the XPS valance spectra of the materials presented in Fig. S12 (a and b) revealed that the VB edge potentials of the so-synthesized LDH and $\mathrm{Fe}_{3} \mathrm{O}_{4}$ were ascertained to be 4.1 and $3.2 \mathrm{eV}$, respectively. Taking account of the obtained band gap energy from the DRS results, the conduction band (CB) of each compound was calculated using Eq. 1.

$\mathrm{E}(\mathrm{VB})=\mathrm{E}(\mathrm{CB})-\mathrm{Eg}$ 
Consequently, the $\mathrm{CB}$ of $\mathrm{Fe}_{3} \mathrm{O}_{4}$ and $\mathrm{LDH}$ was calculated to be 1.35 and $-0.15 \mathrm{eV}$. The achieved results have good accordance with the previously reported results in the published paper [56]. Considering the optical results presented in Fig. S3, although pure magnetite is not visible-light-responsive, its heterojunction with the LDH possessing narrower bandgap, resulted in a significant red-shift in the bandgap of the composite. The decreased bandgap and high ability of the composite in absorbing visible light are in favor of producing more photogenerated charges. This phenomenon facilitates the photocatalytic performance in the degradation of pollutants which was thoroughly confirmed in section 3.2.

This phenomenon was more supported with the high resolution XPS spectra of $\mathrm{Cu} 2 \mathrm{p}, \mathrm{Cr}$ 2p, and $\mathrm{Fe} 2 \mathrm{p}$ in the samples of $\mathrm{Fe}_{3} \mathrm{O}_{4}, \mathrm{CuCr}-\mathrm{LDH}, \mathrm{Fe}_{3} \mathrm{O}_{4} @ \mathrm{CuCr}-\mathrm{LDH}$ composite (Fig. 6). According to the results, the binding energy of $\mathrm{Cu} 2 \mathrm{p}$ and $\mathrm{Cr} 2 \mathrm{p}$ were high for the pure $\mathrm{LDH}$; however, in the composite, it shifted towards the lower binding energies. Moreover, the detected peaks in the high-resolution XPS spectra of Fe 2p for the composite shifted to the higher binding energies relative to that of pure $\mathrm{Fe}_{3} \mathrm{O}_{4}$. Considering the literature review, the appeared opposite shifts of the binding energies are good evidence for the appropriate interfacial contact of $\mathrm{Fe}_{3} \mathrm{O}_{4}$ to the $\mathrm{LDH}$ which leads to the flow of electrons from $\mathrm{Fe}_{3} \mathrm{O}_{4}$ to LDH and equilibrium the Fermi levels [16]. Hence, an internal electric field pointing from $\mathrm{Fe}_{3} \mathrm{O}_{4}$ to $\mathrm{LDH}$ would form at the interface of the catalyst which can result in the upward and downward bending of the band edges for $\mathrm{Fe}_{3} \mathrm{O}_{4}$ and $\mathrm{CuCr}-\mathrm{LDH}$, respectively. Also, Meng and et al. [57] reported the opposite shift of binding energies for Ti 2p, O 1s, Cd 3d, and S 2p. This was reported to be ascribed to the effective electron transference from $\mathrm{CdS}$ to $\mathrm{TiO}_{2}$. Moreover, considering the results displayed in Fig. 6, after the visible light irradiation of composite, the related binding energies of $\mathrm{Cu} 2 \mathrm{p}$ and $\mathrm{Cr} 2 \mathrm{p}$ changed to the higher binding energies and the corresponding peaks of Fe $2 \mathrm{p}$ were found to appear in the lower binding energies. As a result, the formation of an internal electric field restricted the transference of 
photogenerated electrons from the $\mathrm{CB}$ of $\mathrm{Fe}_{3} \mathrm{O}_{4}$ to the $\mathrm{CB}$ of $\mathrm{LDH}$. Therefore; the photogenerated electrons went through a different pathway which left the photogenerated electrons and holes in the $\mathrm{CB}$ of $\mathrm{Fe}_{3} \mathrm{O}_{4}$ and $\mathrm{VB}$ of $\mathrm{LDH}$, respectively. Different methods such as ESR, or photoluminescence (PL) spectroscopy in the presence of different radical scavengers have been used for the confirmation of the charge carrier transference mechanism of the photocatalysts [58,59]. Therefore, in order to further confirm the S-scheme mechanism, we used the ${ }^{\circ} \mathrm{OH}$ trapping method in which non-fluorescence terephthalic acid (TA) can be used as the probe agent [17]. In the course of the reaction between generated ${ }^{\circ} \mathrm{OH}$ with TA, a fluorescent 2-hydroxyterephthalic acid (HTA) can be produced which can be followed by the fluorescence spectroscopy. Fig. 6 ( $a$ and b) demonstrates the fluorescence spectra of HTA for $\mathrm{Fe}_{3} \mathrm{O}_{4}, \mathrm{CuCrLDH}$, and $\mathrm{Fe}_{3} \mathrm{O}_{4} @ \mathrm{CuCrLDH}$ in the absence of oxygen and the presence of EDTA as the hole scavenger. As discussed before the pure magnetite showed no production of ${ }^{\circ} \mathrm{OH}$ under the visible light irradiation. In the absence of $\mathrm{O}_{2}$, the pure $\mathrm{CuCrLDH}$ composite was capable of generating ${ }^{\circ} \mathrm{OH}$ revealing the presence of photogenerated $\mathrm{h}^{+}$with sufficient oxidation potential. On the contrary, according to the results, the presence of EDTA as the $\mathrm{h}^{+}$ inhibitor brought about no fluorescent peak for the pristine $\mathrm{LDH}$ due to its lower $\mathrm{CB}$ position for the reduction of $\mathrm{O}_{2}\left(\mathrm{E}_{\mathrm{O} 2 / 02 \cdot-}=-0.046 \mathrm{eV}\right)(\mathrm{Fig} .6(\mathrm{~b}))$. Also, the synthesized composite showed the fluorescent peak in the presence and absence of EDTA and $\mathrm{O}_{2}$, respectively. 

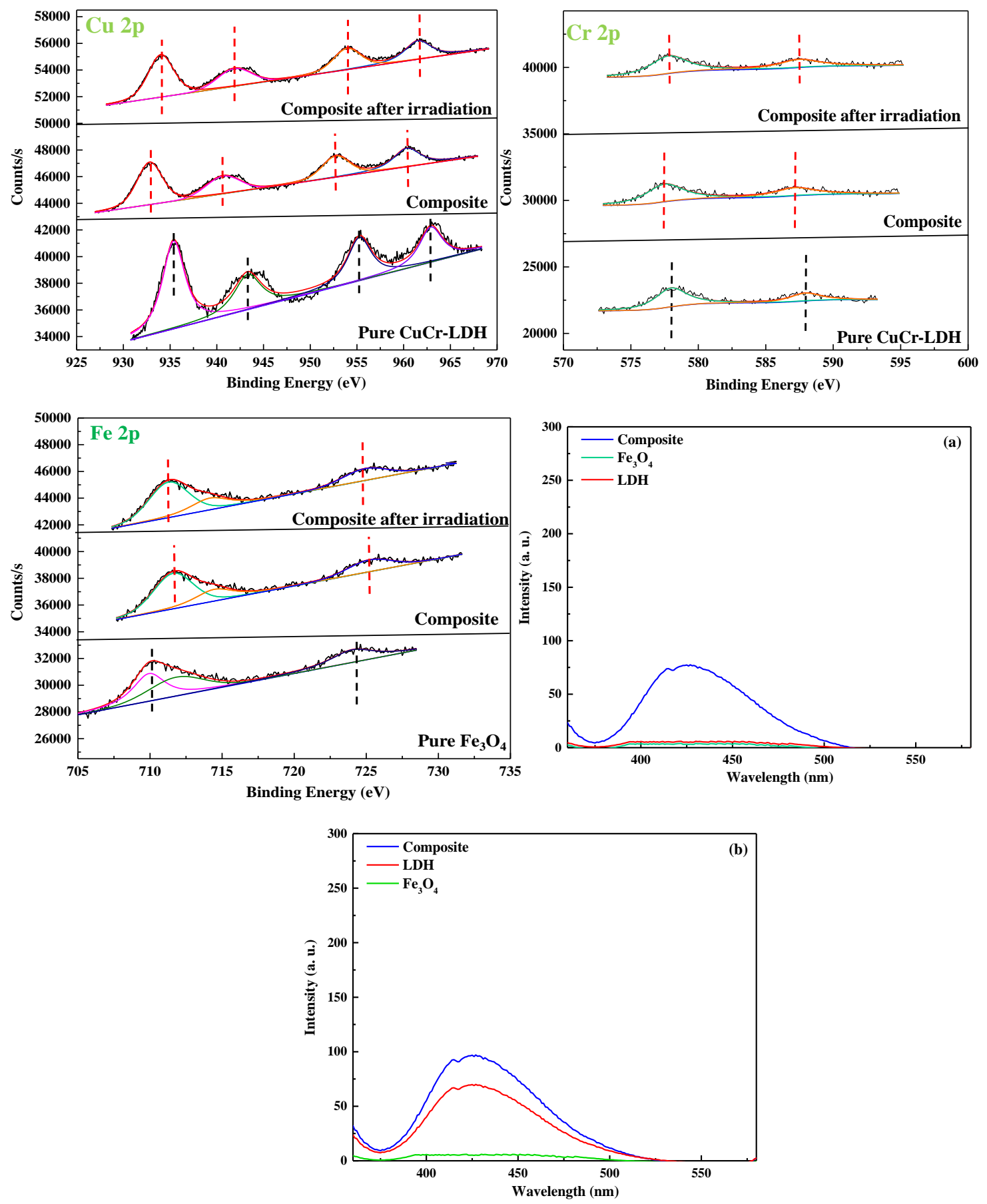

Fig. 6. Comparison of $\mathrm{Cu} 2 \mathrm{p}, \mathrm{Cr} 2 \mathrm{p}$, and $\mathrm{Fe} 2 \mathrm{p}$ XPS spectra for the pure $\mathrm{Fe}_{3} \mathrm{O}_{4}, \mathrm{CuCr}-\mathrm{LDH}$, and $\mathrm{Fe}_{3} \mathrm{O}_{4} @ \mathrm{CuCr}-\mathrm{LDH}$ in the dark and after the visible light irradiation. Fluorescence spectra of $\mathrm{Fe}_{3} \mathrm{O}_{4} @ \mathrm{CuCr}-\mathrm{LDH}, \mathrm{CuCr}-\mathrm{LDH}, \mathrm{Fe}_{3} \mathrm{O}_{4}$ in the presence of EDTA (a) and in the absence of oxygen (b). 
Based on the above results, in our system $\mathrm{Fe}_{3} \mathrm{O}_{4}$ with higher $\mathrm{CB}$ acts as the reduction photocatalyst (SC (I)) and CuCr-LDH forms the oxidation photocatalyst (SC (II)). The composition of magnetite and $\mathrm{CuCr}-\mathrm{LDH}$ results in the type (II) heterojunction. However, in the case of being a type (II) heterojunction, the photogenerated electrons should have been gathered on the $\mathrm{CB}$ of $\mathrm{CuCr}-\mathrm{LDH}$ and were able to reduce $\mathrm{O}_{2}$. With respect to the results obtained from the XPS spectra as well as the produced hydroxyl radicals, the S-scheme charge-carrier migration mechanism was proposed for the photocatalyst (Fig. 7). Accordingly, the useless photogenerated holes and electrons from $\mathrm{Fe}_{3} \mathrm{O}_{4}$ and $\mathrm{CuCr}-\mathrm{LDH}$ combine introducing a strong redox potential

(b)

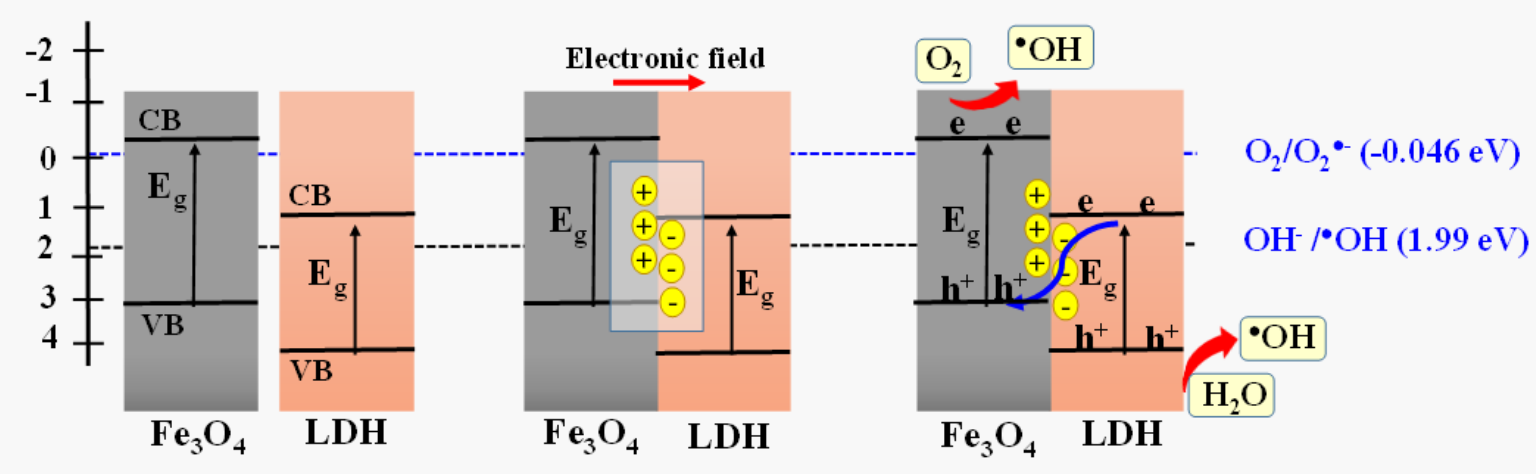

Before contact

After contact

After contact upon irradiation

Fig. 7. The proposed S-scheme schematic mechanism for the charge-carrier migration on the $\mathrm{Fe}_{3} \mathrm{O}_{4} @ \mathrm{CuCrLDH}$ heterojunction.

\subsection{The reusability and stability of $\mathrm{Fe}_{3} \mathrm{O}_{4} @ \mathrm{CuCr}-\mathrm{LDH}$}

One of the essential criteria for the practical application of the so-synthesized nanomaterials is their reusability and stability under the degradation processes $[17,22,60]$. In this regard, under the same operational conditions, the activity of the prepared composite was 
evaluated over five consecutive cycles. To this end, the spent photocatalyst was collected after each of the cycles and dried to be reused in the other cycle of the degradation process. The degradation efficiency of DEP calculated after each reaction run was demonstrated in Fig. S13 (a). Taking consideration of the obtained results, the photocatalytic efficiency of $\mathrm{Fe}_{3} \mathrm{O}_{4} @ \mathrm{CuCr}-\mathrm{LDH}$ was maintained after five consecutive reactions preserving the degradation efficiency of DEP over $65 \%$. Not only do the robustness and reusability of the composite were affirmed by consecutive reaction runs, but also the metal leaching of either $\mathrm{Cu}, \mathrm{Cr}$, and $\mathrm{Fe}$ was determined by the ICP analysis. Using ICP-AES, no more leaching of $\mathrm{Cu}$, $\mathrm{Cr}$, and $\mathrm{Fe}$ was observed which were found to be lower than $1.5 \mu \mathrm{g} \mathrm{L} \mathrm{L}^{-1}$. Nevertheless, the World Health Organization (WHO) has reported the iron, chromium, and copper standard

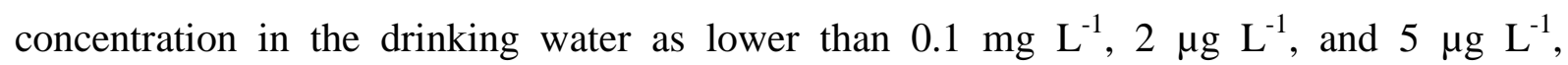
respectively [61].

Moreover, as reported in the Supplementary section, the XPS survey spectrum of the postutilized composite was recorded and compared with the fresh samples. Thus, Fig. S13 (b) evidences a few changes in the overall spectrum indicating the high stability of the sosynthesized nanocomposite.

\section{Conclusion}

In summary, we have proved that $\mathrm{Fe}_{3} \mathrm{O}_{4} @ \mathrm{CuCr}-\mathrm{LDH}$ nanocomposite acts as a promising S-scheme nano-hetrojunction for the efficient activation of peroxymonosulfate. Moreover, it was affirmed that under visible light irradiation, the photocatalytic activity of the sosynthesized photocatalysts was in the order of $\mathrm{Fe}_{3} \mathrm{O}_{4} @ \mathrm{CuCr}-\mathrm{LDH}>\mathrm{CuCr}-\mathrm{LDH}>\mathrm{Fe}_{3} \mathrm{O}_{4}$. Under the determined optimal conditions, the Vis-light/ $/ \mathrm{Fe}_{3} \mathrm{O}_{4} @ \mathrm{CuCr}-\mathrm{LDH} / \mathrm{PMS}$ process showed a proper synergistic effect for increasing the degradation efficiency of DEP. The appropriate degradation efficiency of DEP in the presence of composite, relies on the 
construction of the S-scheme electron transport mechanism which in turn results in the higher separation of electron-hole as well as retaining of the redox ability. At the same time, the $\mathrm{Fe}_{3} \mathrm{O}_{4} @ \mathrm{CuCr}-\mathrm{LDH}$ nanocomposite preserved its structure and photocatalytic properties after 5 cycles of the photocatalytic degradation processes, promising the outstanding performance of the so-synthesized nanocomposite for its application in the other degradation processes. Importantly, the radical trapping tests illustrated the more contribution of $\mathrm{SO}_{4}{ }^{-}$and ${ }^{\circ} \mathrm{OH}$ in the degradation of DEP. We hopefully expect that our current study will provide a new perspective in the synthesis and application of magnetically separable S-scheme photocatalysts for the activation of peroxymonosulfate and degradation of different newly emerged water contaminants. Finally, the easy recovery of the catalyst, its stability, the $\mathrm{pH}$ range close to neutral, and the use of visible light make this system very favorable in the approach of sustainable development for water treatment.

\section{Acknowledgments}

The authors appreciate Dr. Guillaume Monier for accomplishing the XPS analysis and Mhammed Banbakkar for conducting the ICP analysis. We acknowledge the French Embassy in Iran, the program PAUSE, the project I-Site CAP 20-25, and PAI (Pack Ambition Recherche) SOLDE from the Region Auvergne Rhône Alpes for the financial support of Arezou Fazli in this project.

\section{References}

[1] C.-D. Dong, C.-W. Chen, T.-B. Nguyen, C.P. Huang, C.-M. Hung, Degradation of phthalate esters in marine sediments by persulfate over $\mathrm{Fe}-\mathrm{Ce} / \mathrm{biochar}$ composites, Chem. Eng. J. 384 (2020) 123301. https://doi.org/10.1016/j.cej.2019.123301.

[2] E. Ahmadi, S. Yousefzadeh, M. Ansari, H.R. Ghaffari, A. Azari, M. Miri, A. Mesdaghinia, R. Nabizadeh, B. Kakavandi, P. Ahmadi, M.Y. Badi, M. Gholami, K. 
Sharafi, M. Karimaei, M. Ghoochani, M.B. Brahmand, S.M. Mohseni, M. Sarkhosh, S. Rezaei, H. Asgharnia, E. Dehghanifard, B. Jafari, A. Mortezapour, V.K. Moghaddam, M.M. Mahmoudi, N. Taghipour, Performance, kinetic, and biodegradation pathway evaluation of anaerobic fixed film fixed bed reactor in removing phthalic acid esters from wastewater, Sci. Rep. 7 (2017) 1-14. https://doi.org/10.1038/srep41020.

[3] C. Ebenau-Jehle, M. Mergelsberg, S. Fischer, T. Brüls, N. Jehmlich, M. von Bergen, M. Boll, An unusual strategy for the anoxic biodegradation of phthalate, ISME J. 11 (2017) 224-236. https://doi.org/10.1038/ismej.2016.91.

[4] B. Wang, Y. Chen, X. Wang, J. Ramkumar, X. Zhang, B. Yu, D. Yang, M. Karpuraranjith, W. Zhang, rGO wrapped trimetallic sulfide nanowires as an efficient bifunctional catalyst for electrocatalytic oxygen evolution and photocatalytic organic degradation, J. Mater. Chem. A. 8 (2020) 13558-13571. https://doi.org/10.1039/D0TA04383D.

[5] X. Lin, Y. Ma, J. Wan, Y. Wang, Y. Li, Co0.59Fe0.41P nanocubes derived from nanoscale metal-organic frameworks for removal of diethyl phthalate by activation of $\begin{array}{lllllll}\text { peroxymonosulfate, } & \text { Appl. } & \text { Catal. } & \text { Gen. } & 589 & \text { (2020) } & 117307 .\end{array}$ https://doi.org/10.1016/j.apcata.2019.117307.

[6] C. Jin, J. Kang, Z. Li, M. Wang, Z. Wu, Y. Xie, Enhanced visible light photocatalytic degradation of tetracycline by $\mathrm{MoS}_{2} / \mathrm{Ag} / \mathrm{g}-\mathrm{C}_{3} \mathrm{~N}_{4}$ Z-scheme composites with $\begin{array}{lllllll}\text { peroxymonosulfate, } & \text { Appl. } & \text { Surf. } & \text { Sci. } & 514 & \text { (2020) } & 146076 .\end{array}$ https://doi.org/10.1016/j.apsusc.2020.146076.

[7] R. Feizi, M. Ahmad, S. Jorfi, F. Ghanbari, Sunset yellow degradation by ultrasound/peroxymonosulfate/ $\mathrm{CuFe}_{2} \mathrm{O}_{4}$ : Influential factors and degradation processes, Korean J. Chem. Eng. 36 (2019) 886-893. https://doi.org/10.1007/s11814-019-0268-0.

[8] R. Li, J. Huang, M. Cai, J. Huang, Z. Xie, Q. Zhang, Y. Liu, H. Liu, W. Lv, G. Liu, 
Activation of peroxymonosulfate by $\mathrm{Fe}$ doped $\mathrm{g}_{-} \mathrm{C}_{3} \mathrm{~N}_{4} /$ graphene under visible light irradiation for Trimethoprim degradation, J. Hazard. Mater. 384 (2020) 121435. https://doi.org/10.1016/j.jhazmat.2019.121435.

[9] X. Zhao, C. Niu, L. Zhang, H. Guo, X. Wen, C. Liang, G. Zeng, Co-Mn layered double hydroxide as an effective heterogeneous catalyst for degradation of organic dyes by activation of peroxymonosulfate, Chemosphere. 204 (2018) 11-21. https://doi.org/10.1016/j.chemosphere.2018.04.023.

[10] Y. Ding, C. Pan, X. Peng, Q. Mao, Y. Xiao, L. Fu, J. Huang, Deep mineralization of bisphenol A by catalytic peroxymonosulfate activation with nano $\mathrm{CuO} / \mathrm{Fe}_{3} \mathrm{O}_{4}$ with strong $\mathrm{Cu}-\mathrm{Fe}$ interaction, $\mathrm{Chem}$. $\quad$ Eng. $\quad$ J. $384 \quad$ (2020) 123378. https://doi.org/10.1016/j.cej.2019.123378.

[11] J. Li, P. Ye, J. Fang, M. Wang, D. Wu, A. Xu, X. Li, Peroxymonosulfate activation and pollutants degradation over highly dispersed $\mathrm{CuO}$ in manganese oxide octahedral $\begin{array}{lllllll}\text { molecular } & \text { sieve, } & \text { Appl. } & \text { Surf. } & \text { Sci. } 422 & \text { (2017) } & \text { 754-762. }\end{array}$ https://doi.org/10.1016/j.apsusc.2017.06.118.

[12] T.S. Rad, A. Khataee, S. Rahim Pouran, Synergistic enhancement in photocatalytic performance of $\mathrm{Ce}$ (IV) and $\mathrm{Cr}$ (III) co-substituted magnetite nanoparticles loaded on reduced graphene oxide sheets, J. Colloid Interface Sci. 528 (2018) 248-262. https://doi.org/10.1016/j.jcis.2018.05.087.

[13] D.N. Ahmed, L.A. Naji, A.A.H. Faisal, N. Al-Ansari, M. Naushad, Waste foundry sand/MgFe-layered double hydroxides composite material for efficient removal of Congo red dye from aqueous solution, Sci. Rep. 10 (2020) 1-12. https://doi.org/10.1038/s41598-020-58866-y.

[14] G.Y.A. El-Reesh, A.A. Farghali, M. Taha, R.K. Mahmoud, Novel synthesis of Ni/Fe layered double hydroxides using urea and glycerol and their enhanced adsorption 
behavior for Cr(VI) removal, Sci. Rep. 10 (2020) 1-20. https://doi.org/10.1038/s41598$020-57519-4$.

[15] H. Zhang, L. Nengzi, Z. Wang, X. Zhang, B. Li, X. Cheng, Construction of $\mathrm{Bi}_{2} \mathrm{O}_{3} / \mathrm{CuNiFe} \mathrm{LDHs}$ composite and its enhanced photocatalytic degradation of lomefloxacin with persulfate under simulated sunlight, J. Hazard. Mater. 383 (2020) 121236. https://doi.org/10.1016/j.jhazmat.2019.121236.

[16] F. He, B. Zhu, B. Cheng, J. Yu, W. Ho, W. Macyk, 2D/2D/OD TiO $2 / \mathrm{C}_{3} \mathrm{~N}_{4} / \mathrm{Ti}_{3} \mathrm{C}_{2} \mathrm{MXene}$ composite S-scheme photocatalyst with enhanced $\mathrm{CO}_{2}$ reduction activity, Appl. Catal. B Environ. 272 (2020) 119006. https://doi.org/10.1016/j.apcatb.2020.119006.

[17] A. Khataee, A. Fazli, F. Zakeri, S.W. Joo, Synthesis of a high-performance Z-scheme 2D/2D WO $\mathrm{W}_{3} @ \mathrm{CoFe}-\mathrm{LDH}$ nanocomposite for the synchronic degradation of the mixture azo dyes by sonocatalytic ozonation process, J. Ind. Eng. Chem. 89 (2020) 301-315. https://doi.org/10.1016/j.jiec.2020.05.026.

[18] M. Zhang, J. Yao, M. Arif, B. Qiu, H. Yin, X. Liu, S. Chen, 0D/2D CeO2/ZnIn2S4 Zscheme heterojunction for visible-light-driven photocatalytic $\mathrm{H}_{2}$ evolution, Appl. Surf. Sci. 526 (2020) 145749. https://doi.org/10.1016/j.apsusc.2020.145749.

[19] Y. Wang, C. Zhu, G. Zuo, Y. Guo, W. Xiao, Y. Dai, J. Kong, X. Xu, Y. Zhou, A. Xie, C. Sun, Q. Xian, 0D/2D $\mathrm{Co}_{3} \mathrm{O}_{4} / \mathrm{TiO}_{2}$ Z-Scheme heterojunction for boosted photocatalytic degradation and mechanism investigation, Appl. Catal. B Environ. 278 (2020) 119298. https://doi.org/10.1016/j.apcatb.2020.119298.

[20] J. Mu, F. Teng, H. Miao, Y. Wang, X. Hu, In-situ oxidation fabrication of 0D/2D $\mathrm{SnO}_{2} / \mathrm{SnS}_{2}$ novel Step-scheme heterojunctions with enhanced photoelectrochemical activity for water splitting, Appl. Surf. Sci. $501 \quad$ (2020) 143974. https://doi.org/10.1016/j.apsusc.2019.143974.

[21] J. Tao, X. Yu, Q. Liu, G. Liu, H. Tang, Internal electric field induced S-scheme 
heterojunction $\mathrm{MoS}_{2} / \mathrm{CoAl} \mathrm{LDH}$ for enhanced photocatalytic hydrogen evolution, J. Colloid Interface Sci. (2020). https://doi.org/10.1016/j.jcis.2020.10.028.

[22] A. Fazli, A. Khataee, M. Brigante, G. Mailhot, Cubic cobalt and zinc co-doped magnetite nanoparticles for persulfate and hydrogen peroxide activation towards the effective photodegradation of Sulfalene, Chem. Eng. J. 404 (2021) 126391. https://doi.org/10.1016/j.cej.2020.126391.

[23] A. Khataee, T.S. Rad, M. Fathinia, The role of clinoptilolite nanosheets in catalytic ozonation process: Insights into the degradation mechanism, kinetics and the toxicity, J. Taiwan Inst. Chem. Eng. 77 (2017) 205-215. https://doi.org/10.1016/j.jtice.2017.05.004.

[24] M. Aghaziarati, Y. Yamini, M. Shamsayei, An electrodeposited terephthalic acid-layered double hydroxide $(\mathrm{Cu}-\mathrm{Cr})$ nanosheet coating for in-tube solid-phase microextraction of phthalate esters, Microchim. Acta. 187 (2020) 118. https://doi.org/10.1007/s00604-019$4102-5$.

[25] J.-Y. Lee, G.-H. Gwak, H.-M. Kim, T. Kim, G.J. Lee, J.-M. Oh, Synthesis of hydrotalcite type layered double hydroxide with various $\mathrm{Mg} / \mathrm{Al}$ ratio and surface charge under controlled reaction condition, Appl. Clay Sci. 134 (2016) 44-49. https://doi.org/10.1016/j.clay.2016.03.029.

[26] H. Zhang, B. Xia, P. Wang, Y. Wang, Z. Li, Y. Wang, L. Feng, X. Li, S. Du, From waste to waste treatment: Mesoporous magnetic $\mathrm{NiFe}_{2} \mathrm{O}_{4} / \mathrm{ZnCuCr}$-layered double hydroxide composite for wastewater treatment, J. Alloys Compd. 819 (2020) 153053. https://doi.org/10.1016/j.jallcom.2019.153053.

[27] Z. Zhang, L. Sun, Z. Wu, Y. Liu, S. Li, Facile hydrothermal synthesis of $\mathrm{CuO}-\mathrm{Cu}_{2} \mathrm{O} / \mathrm{GO}$ nanocomposites for the photocatalytic degradation of organic dye and tetracycline pollutants, New J. Chem. 44 (2020) 6420-6427. https://doi.org/10.1039/D0NJ00577K.

[28] T.S. Rad, A. Khataee, S. Rahim Pouran, Synergistic enhancement in photocatalytic 
performance of $\mathrm{Ce}$ (IV) and $\mathrm{Cr}$ (III) co-substituted magnetite nanoparticles loaded on reduced graphene oxide sheets, J. Colloid Interface Sci. 528 (2018) 248-262. https://doi.org/10.1016/j.jcis.2018.05.087.

[29] A.S. Patil, J.L. Gunjakar, C.D. Lokhande, U.M. Patil, S.V. Sadavar, N.S. Padalkar, R.B. Shinde, M.M. Wagh, J.S. Bagi, Nanocrystalline copper-chromium-layered double hydroxide with tunable interlayer anions for electrochemical capacitor application, Synth. Met. 264 (2020) 116371. https://doi.org/10.1016/j.synthmet.2020.116371.

[30] A. Pastor, F. Rodriguez-Rivas, G. de Miguel, M. Cruz-Yusta, F. Martin, I. Pavlovic, L. Sánchez, Effects of $\mathrm{Fe}^{3+}$ substitution on $\mathrm{Zn}-\mathrm{Al}$ layered double hydroxides for enhanced NO photochemical abatement, Chem. Eng. J. $387 \quad(2020) 124110$. https://doi.org/10.1016/j.cej.2020.124110.

[31] Y. Meng, T. Dai, X. Zhou, G. Pan, S. Xia, Photodegradation of volatile organic compounds catalyzed by MCr-LDHs and hybrid MO@MCr-LDHs $(\mathrm{M}=\mathrm{Co}, \mathrm{Ni}, \mathrm{Cu}$, $\mathrm{Zn):} \mathrm{the} \mathrm{comparison} \mathrm{of} \mathrm{activity,} \mathrm{kinetics} \mathrm{and} \mathrm{photocatalytic} \mathrm{mechanism,} \mathrm{Catal.} \mathrm{Sci.}$ Technol. 10 (2020) 424-439. https://doi.org/10.1039/C9CY02098E.

[32] W. Wang, J. Zhang, T. Chen, J. Sun, X. Ma, Y. Wang, J. Wang, Z. Xie, Preparation of $\mathrm{TiO}_{2}$-modified Biochar and its Characteristics of Photo-catalysis Degradation for Enrofloxacin, Sci. Rep. 10 (2020) 1-12. https://doi.org/10.1038/s41598-020-62791-5.

[33] A. Maleki, Z. Hajizadeh, P. Salehi, Mesoporous halloysite nanotubes modified by $\mathrm{CuFe}_{2} \mathrm{O}_{4}$ spinel ferrite nanoparticles and study of its application as a novel and efficient heterogeneous catalyst in the synthesis of pyrazolopyridine derivatives, Sci. Rep. 9 (2019) 1-8. https://doi.org/10.1038/s41598-019-42126-9.

[34] Y. Liu, Y. Liu, H. Shi, M. Wang, S.H.-S. Cheng, H. Bian, M. Kamruzzaman, L. Cao, C.Y. Chung, Z. Lu, Cobalt-copper layered double hydroxide nanosheets as high performance bifunctional catalysts for rechargeable lithium-air batteries, J. Alloys 
Compd. 688 (2016) 380-387. https://doi.org/10.1016/j.jallcom.2016.07.224.

[35] P. Gholami, L. Dinpazhoh, A. Khataee, A. Hassani, A. Bhatnagar, Facile hydrothermal synthesis of novel $\mathrm{Fe}-\mathrm{Cu}$ layered double hydroxide/biochar nanocomposite with enhanced sonocatalytic activity for degradation of cefazolin sodium, J. Hazard. Mater. 381 (2020) 120742. https://doi.org/10.1016/j.jhazmat.2019.120742.

[36] S. Sarkar, R. Akshaya, S. Ghosh, Nitrogen doped graphene/ $\mathrm{CuCr}_{2} \mathrm{O}_{4}$ nanocomposites for supercapacitors application: Effect of nitrogen doping on coulombic efficiency, Electrochimica

Acta.

332

(2020)

135368. https://doi.org/10.1016/j.electacta.2019.135368.

[37] C. Dong, X. Zhang, J. Xu, R. Si, J. Sheng, J. Luo, S. Zhang, W. Dong, G. Li, W. Wang, F. Huang, Ruthenium-Doped Cobalt-Chromium Layered Double Hydroxides for Enhancing Oxygen Evolution through Regulating Charge Transfer, Small. 16 (2020) 1905328. https://doi.org/10.1002/smll.201905328.

[38] C.M. Navarathna, N.B. Dewage, A.G. Karunanayake, E.L. Farmer, F. Perez, E.B. Hassan, T.E. Mlsna, C.U. Pittman, Rhodamine B Adsorptive Removal and Photocatalytic Degradation on MIL-53-Fe MOF/Magnetic Magnetite/Biochar Composites, J. Inorg. Organomet. Polym. Mater. 30 (2020) 214-229. https://doi.org/10.1007/s10904-019-01322-w.

[39] S.J. Ki, Y.-K. Park, J.-S. Kim, W.-J. Lee, H. Lee, S.-C. Jung, Facile preparation of tungsten oxide doped $\mathrm{TiO} 2$ photocatalysts using liquid phase plasma process for enhanced degradation of diethyl phthalate, Chem. Eng. J. 377 (2019) 120087. https://doi.org/10.1016/j.cej.2018.10.024.

[40] R. Yu, J. Zhao, Z. Zhao, F. Cui, Copper substituted zinc ferrite with abundant oxygen vacancies for enhanced ciprofloxacin degradation via peroxymonosulfate activation, J. Hazard. Mater. 390 (2020) 121998. https://doi.org/10.1016/j.jhazmat.2019.121998. 
[41] Z. Li, D. Liu, Y. Zhao, S. Li, X. Wei, F. Meng, W. Huang, Z. Lei, Singlet oxygen dominated peroxymonosulfate activation by $\mathrm{CuO}-\mathrm{CeO} 2$ for organic pollutants degradation: Performance and mechanism, Chemosphere. 233 (2019) 549-558. https://doi.org/10.1016/j.chemosphere.2019.05.291.

[42] C. Liu, L. Liu, X. Tian, Y. Wang, R. Li, Y. Zhang, Z. Song, B. Xu, W. Chu, F. Qi, A. Ikhlaq, Coupling metal-organic frameworks and $\mathrm{g}-\mathrm{C}_{3} \mathrm{~N}_{4}$ to derive Fe@N-doped graphene-like carbon for peroxymonosulfate activation: Upgrading framework stability and performance, Appl. Catal. B Environ. $255 \quad$ (2019) 117763. https://doi.org/10.1016/j.apcatb.2019.117763.

[43] S. Wang, J. Wang, Activation of peroxymonosulfate by sludge-derived biochar for the degradation of triclosan in water and wastewater, Chem. Eng. J. 356 (2019) 350-358. https://doi.org/10.1016/j.cej.2018.09.062.

[44] X. Duan, S. Yang, S. Wacławek, G. Fang, R. Xiao, D.D. Dionysiou, Limitations and prospects of sulfate-radical based advanced oxidation processes, J. Environ. Chem. Eng. 8 (2020) 103849. https://doi.org/10.1016/j.jece.2020.103849.

[45] W. Sang, Z. Li, M. Huang, X. Wu, D. Li, L. Mei, J. Cui, Enhanced transition metal oxide based peroxymonosulfate activation by hydroxylamine for the degradation of $\begin{array}{lllllll}\text { sulfamethoxazole, } & \text { Chem. } & \text { Eng. } & \text { J. } & 383 & \text { (2020) } & 123057 .\end{array}$ https://doi.org/10.1016/j.cej.2019.123057.

[46] Z. Yin, M. Han, Z. Hu, L. Feng, Y. Liu, Z. Du, L. Zhang, Peroxymonosulfate enhancing visible light photocatalytic degradation of bezafibrate by $\mathrm{Pd} / \mathrm{g}-\mathrm{C}_{3} \mathrm{~N}_{4}$ catalysts: The role of sulfate radicals and hydroxyl radicals, Chem. Eng. J. 390 (2020) 124532. https://doi.org/10.1016/j.cej.2020.124532.

[47] C. Cai, H. Zhang, X. Zhong, L. Hou, Ultrasound enhanced heterogeneous activation of peroxymonosulfate by a bimetallic $\mathrm{Fe}-\mathrm{Co} / \mathrm{SBA}-15$ catalyst for the degradation of 
Orange II in water, J. Hazard. Mater. 283 (2015) 70-79. https://doi.org/10.1016/j.jhazmat.2014.08.053.

[48] F. Ghanbari, J. Wu, M. Khatebasreh, D. Ding, K.-Y.A. Lin, Efficient treatment for landfill leachate through sequential electrocoagulation, electrooxidation and PMS/UV/CuFe $\mathrm{O}_{4}$ process, Sep. Purif. Technol. $242 \quad$ (2020) 116828. https://doi.org/10.1016/j.seppur.2020.116828.

[49] Y. Tao, Q. Ni, M. Wei, D. Xia, X. Li, A. Xu, Metal-free activation of peroxymonosulfate by $\mathrm{g}-\mathrm{C}_{3} \mathrm{~N}_{4}$ under visible light irradiation for the degradation of organic dyes, RSC Adv. 5 (2015) 44128-44136. https://doi.org/10.1039/C5RA06223C.

[50] N.S. Shah, J.A. Khan, M. Sayed, Z.U.H. Khan, A.D. Rizwan, N. Muhammad, G. Boczkaj, B. Murtaza, M. Imran, H.M. Khan, G. Zaman, Solar light driven degradation of norfloxacin using as-synthesized $\mathrm{Bi}^{3+}$ and $\mathrm{Fe}^{2+}$ co-doped $\mathrm{ZnO}$ with the addition of $\mathrm{HSO}_{5}{ }^{-}$: Toxicities and degradation pathways investigation, Chem. Eng. J. 351 (2018) 841-855. https://doi.org/10.1016/j.cej.2018.06.111.

[51] A. Khataee, A. Fazli, M. Fathinia, F. Vafaei, Preparation of martite nanoparticles through high-energy planetary ball milling and its application toward simultaneous catalytic ozonation of two green algae, J. Taiwan Inst. Chem. Eng. 82 (2018) 80-91. https://doi.org/10.1016/j.jtice.2017.10.016.

[52] M. Golshan, B. Kakavandi, M. Ahmadi, M. Azizi, Photocatalytic activation of peroxymonosulfate by $\mathrm{TiO} 2$ anchored on cupper ferrite $\left(\mathrm{TiO}_{2} @ \mathrm{CuFe}_{2} \mathrm{O}_{4}\right)$ into 2,4-D degradation: Process feasibility, mechanism and pathway, J. Hazard. Mater. 359 (2018) 325-337. https://doi.org/10.1016/j.jhazmat.2018.06.069.

[53] Y. Zhong, Z.-F. Chen, S.-C. Yan, W.-W. Wei, Q. Zhang, G. Liu, Z. Cai, L. Yu, Photocatalytic transformation of climbazole and 4-chlorophenol formation using a floral array of chromium-substituted magnetite nanoparticles activated with 
peroxymonosulfate, Environ. Sci. Nano. $6 \quad$ (2019) 2986-2999. https://doi.org/10.1039/C9EN00673G.

[54] J. Lin, Y. Hu, L. Wang, D. Liang, X. Ruan, S. Shao, M88/PS/Vis system for degradation of bisphenol A: Environmental factors, degradation pathways, and toxicity evaluation, Chem. Eng. J. 382 (2020) 122931. https://doi.org/10.1016/j.cej.2019.122931.

[55] T. Cai, W. Zeng, Y. Liu, L. Wang, W. Dong, H. Chen, X. Xia, A promising inorganicorganic Z-scheme photocatalyst Ag3PO4/PDI supermolecule with enhanced photoactivity and photostability for environmental remediation, Appl. Catal. B Environ. 263 (2020) 118327. https://doi.org/10.1016/j.apcatb.2019.118327.

[56] Z. Yang, C. Zhang, G. Zeng, X. Tan, H. Wang, D. Huang, K. Yang, J. Wei, C. Ma, K. Nie, Design and engineering of layered double hydroxide based catalysts for water depollution by advanced oxidation processes: a review, J. Mater. Chem. A. 8 (2020) 4141-4173. https://doi.org/10.1039/C9TA13522G.

[57] A. Meng, B. Zhu, B. Zhong, L. Zhang, B. Cheng, Direct Z-scheme $\mathrm{TiO}_{2} / \mathrm{CdS}$ hierarchical photocatalyst for enhanced photocatalytic $\mathrm{H}_{2}$-production activity, Appl. Surf. Sci. 422 (2017) 518-527. https://doi.org/10.1016/j.apsusc.2017.06.028.

[58] A. Kumar, M. Khan, J. He, I.M.C. Lo, Visible-light-driven magnetically recyclable terephthalic acid functionalized $\mathrm{g}-\mathrm{C}_{3} \mathrm{~N}_{4} / \mathrm{TiO}_{2}$ heterojunction nanophotocatalyst for enhanced degradation of PPCPs, Appl. Catal. B Environ. 270 (2020) 118898. https://doi.org/10.1016/j.apcatb.2020.118898.

[59] B. Palanivel, A. Mani, Conversion of a Type-II to a Z-Scheme Heterojunction by Intercalation of a $0 \mathrm{D}$ Electron Mediator between the Integrative $\mathrm{NiFe}_{2} \mathrm{O}_{4} / \mathrm{g}-\mathrm{C}_{3} \mathrm{~N}_{4}$ Composite Nanoparticles: Boosting the Radical Production for Photo-Fenton Degradation, $\quad$ ACS $\quad$ Omega. $\quad 5 \quad$ (2020) 19747-19759. https://doi.org/10.1021/acsomega.0c02477. 
[60] F. Ghanbari, J. Wu, M. Khatebasreh, D. Ding, K.-Y.A. Lin, Efficient treatment for landfill leachate through sequential electrocoagulation, electrooxidation and PMS/UV/CuFe $\mathrm{O}_{4}$ process, Sep. Purif. Technol. $242 \quad$ (2020) 116828. https://doi.org/10.1016/j.seppur.2020.116828.

[61] M. Kumar, A. Puri, A review of permissible limits of drinking water, Indian J. Occup. Environ. Med. 16 (2012) 40-44. https://doi.org/10.4103/0019-5278.99696. 